\title{
THE INFLUENCE OF GEOMETRICAL AND OPERATIONAL PARAMETERS ON INTERNAL FLOW CHARACTERISTICS OF INTERNALLY MIXING TWIN-FLUID Y-JET ATOMIZERS
}

\author{
Y.H. Nazeer, ${ }^{1, *}$ M. Ehmann, ${ }^{1}$ P. Koukouvinis, ${ }^{2}$ \& M. Gavaises ${ }^{2}$ \\ ${ }^{1}$ Mitsubishi Hitachi Power Systems Europe GmbH, Germany \\ ${ }^{2}$ School of Mathematics, Computer Sciences and Engineering, City University of \\ London, United Kingdom \\ *Address all correspondence to: Y.H. Nazeer, Mitsubishi Hitachi Power Systems Europe \\ GmbH, Germany; Tel.: +49 2038038 1354; Fax: +49 2038038611 354, \\ E-mail: y_nazeer@eu.mhps.com \\ Original Manuscript Submitted: 5/7/2019; Final Draft Received: 8/14/2019
}

\begin{abstract}
Internally mixing twin-fluid $Y$-jet atomizers are widely used in coal-fired thermal power plants for start-up, oil-fired thermal power plants, and industrial boilers. The flow through internally mixing $Y$-jet atomizers is numerically modeled using the compressible Navier-Stokes equations; wall modeled large eddy simulations (WMLES) are used to resolve the turbulence with large eddy simulations whereas the Prandtl mixing length model is used for modeling the subgrid scale structures, which are affected by geometric and operational parameters. Moreover, the volume-of-fluid (VOF) method is used to capture the development and fragmentation of the liquid-gas interface within the Y-jet atomizer. The numerical results are compared with correlations available in the open literature for the pressure drop; further results are presented for the multiphase flow regime maps available for vertical pipes. The results show that the mixing point pressure is strongly dependent on the mixing port diameter to air port diameter ratio, specifically for gas to liquid mass flow-rate ratio (GLR) in the range $0.1<G L R<0.4$; the mixing port length moderately affects the mixing point pressure while the angle between mixing and liquid ports is found not to have an appreciable effect. Moreover, it is found that the vertical pipe multiphase flow regime maps in the literature could be applied to the flow through the mixing port of the twin-fluid Y-jet atomizer. The main flow regimes found under the studied operational conditions are annular and wispy-annular flow.
\end{abstract}

KEY WORDS: internally mixing twin-fluid Y-jet atomizer, compressible volume of fluid, large eddy simulations, multiphase flow regimes

\section{INTRODUCTION}

Twin-fluid atomizers have been used in numerous industrial applications over the years such as gas turbines (Lefebvre, 1988), internal combustion engines (Wade et al., 1999), spray drying (Mujumdar et al., 2010), spray coating (Esfarjani and Dolatabadi, 2009), scramjet engines (Gadgil and Raghunandan, 2011), fire suppression (Huang et al., 2011), process industries (Loebker and Empie, 1997), and power plants (Zhou et al., 2010). They use compressed air or steam 


\section{NOMENCLATURE}

\begin{tabular}{|c|c|c|c|}
\hline$A$ & parameter defined in Eq. (19) & $\Delta$ & modified length scale (m) \\
\hline$C_{w}$ & empirical constant & $\delta$ & Kronecker delta \\
\hline$C_{\text {smag }}$ & Smagorinsky constant & $\theta$ & angle $\left(^{\circ}\right)$ \\
\hline$c$ & speed of sound $(\mathrm{m} / \mathrm{s})$ & $\mu$ & viscosity $(\mathrm{kg} / \mathrm{m} \cdot \mathrm{s})$ \\
\hline$d$ & diameter $(\mathrm{m})$ & $\mu_{l}^{\prime}$ & ratio of liquid viscosity to water \\
\hline$d_{w}$ & distance from wall $(\mathrm{m})$ & & viscosity at standard conditions \\
\hline$E$ & energy $(\mathrm{J})$ & $\rho$ & density $\left(\mathrm{kg} / \mathrm{m}^{3}\right)$ \\
\hline $\mathrm{Fr}_{\mathrm{tp}}$ & two-phase Froude number & $\rho_{l}^{\prime}$ & ratio of liquid density to water \\
\hline$G$ & mass velocity $\left(\mathrm{kg} / \mathrm{m}^{2} \cdot \mathrm{s}\right)$ & & density at standard conditions \\
\hline$g$ & gravitational acceleration $\left(\mathrm{m} / \mathrm{s}^{2}\right)$ & $\sigma$ & surface tension $(\mathrm{N} / \mathrm{m})$ \\
\hline$h_{\max }$ & maximum edge length (m) & $\sigma_{l}^{\prime}$ & ratio of liquid surface tension to \\
\hline$h_{\mathrm{wn}}$ & $\begin{array}{l}\text { grid step in wall normal } \\
\text { direction }(\mathrm{m})\end{array}$ & & $\begin{array}{l}\text { water surface tension at standard } \\
\text { conditions }\end{array}$ \\
\hline$J$ & superficial velocity $(\mathrm{m} / \mathrm{s})$ & $\tau$ & Reynold stress tensor $\left(\mathrm{N} / \mathrm{m}^{2}\right)$ \\
\hline$K_{\text {eff }}$ & effective thermal conductivity & $\overline{\bar{\tau}}$ & viscous stress tensor $\left(\mathrm{kg} / \mathrm{m} \cdot \mathrm{s}^{2}\right)$ \\
\hline & $(\mathrm{W} / \mathrm{m} \cdot \mathrm{K})$ & $\Omega$ & vorticity (s-1) \\
\hline$k$ & curvature $\left(\mathrm{m}^{-1}\right)$ & $\varphi$ & momentum ratio \\
\hline$l$ & length (mm) & & \\
\hline$\dot{m}$ & mass flow rate $(\mathrm{kg} / \mathrm{s})$ & \multicolumn{2}{|c|}{ Subscripts } \\
\hline$P$ & pressure $(\mathrm{Pa})$ & \multirow{2}{*}{1,2} & points along the length \\
\hline$Q$ & volume flow rate $\left(\mathrm{m}^{3}\right)$ & & of mixing-port \\
\hline$R$ & radius $(\mathrm{m})$ & $a$ & air \\
\hline$S$ & strain rate $\left(\mathrm{s}^{-1}\right)$ & $G$ & gas \\
\hline$T_{\sigma}$ & surface tension force $(\mathrm{N})$ & $i, j, k$ & direction vector \\
\hline$T$ & temperature $(\mathrm{K})$ & $p$ & phase $p$ \\
\hline$V$ & velocity $(\mathrm{m} / \mathrm{s})$ & $q$ & phase $q$ \\
\hline$V_{r}$ & relative velocity $(\mathrm{m} / \mathrm{s})$ & $l$ & liquid \\
\hline$v_{t}$ & eddy viscosity $\left(\mathrm{m}^{2} / \mathrm{s}\right)$ & $m$ & mixing point \\
\hline We & Weber number & $\max$ & maximum \\
\hline$y^{+}$ & dimensionless wall distance & $\min$ & minimum \\
\hline \multirow[t]{2}{*}{$Z$} & coordinate along the length & $w$ & water \\
\hline & & \multicolumn{2}{|c|}{ Superscripts } \\
\hline \multicolumn{2}{|c|}{ Greek Symbols } & $s$ & subgrid scale \\
\hline$\alpha$ & volume fraction & $T$ & transpose \\
\hline
\end{tabular}

to augment the atomization process; they are classified into internally and externally mixing twin-fluid atomizers. In externally mixing atomizers, high-velocity gas or steam impinges on the liquid just outside the discharge orifice, while in internally mixing ones, the gas or steam mixes with the liquid inside the nozzle before being injected. In the internal mixing type, the spray 
cone angle is minimum for maximum gas flow while the spray widens as gas flow reduces. This type of atomizer is well suited for highly viscous liquids as good atomization could be obtained at low liquid flow rates (Barreras et al., 2008). It is far more efficient than the externally mixing concept as lower gas flow rates are needed to achieve the same degree of atomization (Tanasawa et al., 1978). However, external mixing atomizers have the advantage of producing sprays with constant spray angle at all liquid flow rates independently of the back pressure, as there is no communication between the flowing media internally.

Undoubtedly, there are various ways to generate the atomized sprays using various types of nozzles, including, for example, rotary cups (Nguyen and Rhodes, 1998), twin fluids (Lefebvre, 1988; Wade et al., 1999; Li et al., 2018; Mujumdar et al., 2010; Esfarjani and Dolatabadi, 2009; Gadgil and Raghunandan, 2011; Huang et al., 2011; Loebker and Empie, 1997; Zhou et al., 2010), pressure swirl (Radcliffe, 1955; Dafsari et al., 2017; Arcoumanis et al., 1999a), fan (Dombrowski et al., 1960), ultrasonic (Lang, 1962), electrostatic (Maski and Durairaj, 2010), diesel injectors (Arcoumanis et al., 1999b; Mitroglou and Gavaises, 2011), and effervescent atomizers (Sovani et al., 2001; Saleh et al., 2018); solid or hollow cone sprays may form depending on the type of atomizer and operating conditions. However, in thermal power plants or oil-fired large industrial boilers, operating with high flow rates of viscous fuel, mostly Y-jet or internal mixing chamber twin-fluid atomizers are used (Barreras et al., 2006b). The former is used with light and medium fuel oil while the latter is used with heavy fuel oil (Li et al., 2012), with steam as auxiliary fluid. An obvious advantage of using the steam is that any heat transfer from the steam to the fuel in the mixing port will enhance atomization by reducing the fuel's viscosity and surface tension. In contrast, the comparative test carried out by Bryce et al. (1978) showed that compressed air produced much finer spray than steam. Barreras et al. (2006a) demonstrated that for the same liquid mass flow rate, the internal mixing chamber twin-fluid atomizer requires a lower atomizing fluid mass flow rate than an equivalent Y-jet one, simultaneously yielding droplets with smaller Sauter mean diameter. The characteristic of the Y-jet atomizer is that liquid and gas (steam or air) are mixed before injected out. It generally consists of a number of jets from a minimum of two to a maximum of 20, arranged in an annular manner to provide hollow conical spray. The advantage of such an atomizer is that it could be operated by keeping constant gas-to-liquid mass flow rate ratio, and the requirement of the atomizing fluid is low. Y-jet atomizers are reported to maintain a moderate emission rate while attaining relatively high atomization efficiency (Pacifico and Yanagihara, 2014). This kind of atomizer creates high relative velocity by injecting gas at high velocity, which induces disturbances in the liquid jet and leads to the creation of smaller liquid ligaments; subsequently, smaller droplets are formed due to the ligament's breakup due to aerodynamically induced surface waves (Dombrowski and Johns, 1963). The high relative velocity of the gas helps dispersion of the liquid and prevents coalescence of droplets (Pacifico and Yanagihara, 2014).

Twin-fluid atomizers have been studied extensively over the years. Most of the studies are focused on prefilming air blast atomizers or effervescent atomizers due to their extensive commercial use. The earlier ones are used extensively in aircraft, marine, and industrial gas turbines and the later ones are used in various applications where low injection pressures and low gas flow rates are available. There exist considerable studies on internally mixing twin-fluid Y-jet atomizers. However, the understanding of this type of nozzle is not very clear owing to complex aerodynamic and fluid dynamic flow pattern due to the mixing of gas and liquid within the mixing chamber.

Mullinger and Chigier (1974) were the first to study the performance of such atomizer systematically. According to them, and as shown pictorially by Song and Lee (1996), some

Volume 29, Issue 5, 2019 
atomization occurs within the mixing chamber, but most of the liquid emanates from the atomizer in the form of liquid that is then shattered into droplets by the atomizing fluid. Mullinger and Chigier (1974) and Prasad (1982) reported an extensive parametric study and proposed design criteria for the Y-jet twin-fluid nozzles. In fact, the results of Mullinger and Chigier showed good agreement with the empirical dimensionless correlation of the mass median diameter for air-blast atomizer proposed by Wigg (1959). It is pertinent to mention here that the choice to name an atomizer as an air-assist or air-blast atomizer is arbitrary. Usually, air-assist atomizers employ very high velocities that usually necessitate an external supply of high-pressure steam/air, while the lower gas requirement of air-blast atomizers can usually be met by utilizing the pressure differential across the combustion liner.

Andreussi et al. (1992) reported that the length to diameter ratio of the mixing port influences the pressure drop, spray structure, and droplet size distribution based on a semiempirical model of the flow inside a twin-fluid Y-jet atomizer. Song and Lee (1994) studied the effect of the mixing port length and the injection pressure on the flow rates of the gas and liquid and droplet size distribution. Andreussi et al. (1994) explained the internal flow conditions and the liquid film thickness inside the mixing duct and postulated their effect on external spray characteristics. Song and Lee (1996) made a pictorial study of the internal flow pattern of the Y-jet atomizer and described the internal flow as annular/annular mist flow (Chin and Lefebvre, 1993); they proposed the main mechanism involved in fuel atomization and linked the internal flow pattern to the droplet size distribution in the spray. Mlkvik et al. (2015) compared the performance of four different internally mixing twin-fluid atomizers for the range of different operating conditions and liquid properties. They found the internally mixing Y-jet atomizer produced the most stable spray regardless of pressure differential and gas to liquid ratio (GLR). The internal flow pattern for the Y-jet atomizer showed strong agreement with the results of Song and Lee (1996) and Nazeer et al. (2018).

Ferreira et al. (2009b) demonstrated that under certain experimental conditions the atomizing fluid flow is choked in an internally mixing chamber twin-fluid atomizer. Sonic conditions are achieved at different mass flow rates as a function of both the air/gas channel diameter and liquid mass flow rate. They found that under choked conditions there is a certain channel diameter that produced the smallest Sauter mean diameters (SMD).

There are two different ways in which two-phase flow is commonly represented in computational fluid dynamics (CFD), namely, the "Eulerian" method, where the flow is considered as continuous across the whole flow domain, and the "Lagrangian" method, where the paths taken by the particles/droplets are tracked through the domain (Jang et al., 2010). In the Lagrangian particle tracking approach, the gas phase is still represented using an Eulerian approach by solving the governing equations of the flow but the liquid spray is represented by a number of discrete "computational particles," which are tracked by solving the particle's equation of the motion. The fundamental assumption made in this approach is that the dispersed secondary phase occupies a low volume fraction (typically bellow 10\%) (El-Batsh et al., 2012). Therefore, this approach is not appropriate to model the multiphase flow within the nozzle where the volumetric effect of the secondary phase cannot be neglected. Eulerian methods could be further classified into single fluid, such as relevant mixture and volume of fluid (VOF) models, and multifluid approaches like Eulerian multiphase and multifluid VOF models (Crowe, 2006; Loth, 2009). The latter approach treats each phase as a single independent phase but with intermixed continua, while the former treats the flow as a single-phase flow by solving a single set of conservation equations considering the mixture properties. The single-fluid approach assumes that the continuous and the dispersed phases are in local kinetic and thermal equilibrium; i.e., the relative velocities and 
temperatures between the two phases are small in comparison to predicted variations of the overall flow field (Lakhehal et al., 2002). The multifluid approach requires a separate conservation equation for each phase, making it extremely computationally expensive and complex; hence, this rules out the possibility of utilizing it for extensive parametric studies. On the other hand, the mixture model solves a smaller number of equations as compared to the aforementioned models; however, it is not possible to track the interface between the phases. This is a major drawback for the studies aiming to identify the relevant flow regimes. The Eulerian surface tracking technique, i.e., the VOF method, can track with relatively good accuracy the interface between the phases; this makes it feasible to study the in-nozzle flow and primary breakup of the jets (Gopala and Berend, 2008). Hence it is considered to be a viable option to model the multiphase flow through a Y-jet atomizer.

Scale resolving technique, i.e., large eddy simulations (LES), has been able to simulate turbulent flows since the 1960s. It has made significant progress over the last two decades specifically due to the surge in computing power. The hybrid LES technique is beginning to emerge as a viable alternative to time-averaged or ensemble-averaged Navier-Stokes (RANS) turbulence modeling in industrial flows; it is able to capture flow structures larger than the grid size, while smaller scales are modeled with subgrid scale models (SGS). The spectrum of resolved scales in LES is directly dependent on the grid resolution. This makes it extremely expensive for industrial scale simulations, which are usually highly turbulent, wall bounded, viscous, and threedimensional flows. Nevertheless, wall modeled LES (WMLES) is a substitute for classical LES and it reduces the stringent and Reynolds number dependent grid resolution requirements of classical wall-resolved LES. Turbulence length scales in near-wall regions are directly proportional to wall distance, resulting in smaller and smaller eddies as the wall is approached (Naseri et al., 2018). This effect is limited by molecular viscosity, which damps out eddies inside the viscous sublayer. Smaller eddies appear as the Reynolds number increases, since the viscous sublayer becomes thinner. In order to circumvent the resolution of these small near-wall scales, RANS and LES models are combined such that the RANS model covers the closest near-wall layer, in which the wall distance is much smaller than boundary-layer thickness but is still potentially very large in wall units (Piomelli and Balaras, 2002). It then switches over to the LES formulation once the grid spacing becomes sufficient to resolve the local scales (Wen and Piomelli, 2016). This approach is similar to detached eddy simulations (Spalart et al., 1997) and delayed detached eddy simulations (Spalart et al., 2006; Koukouvinis et al., 2016b). A general approach of these two approaches is that the whole or major part of the boundary layer is modeled by RANS while LES is applied only to separated flow regions. In contrast, as aforementioned, in WMLES, RANS is used only in very thin near-wall region (Koukouvinis et al., 2016a).

There is a dearth of numerical studies on internally mixing twin-fluid Y-jet atomizers, probably owing to the complexity involved in modeling the complex multiphase flow pattern due to variations in length and time scales. However, there exist a few numerical studies such as Tanner et al. (2016) which focuses on the atomization and droplet breakup in annular gas-liquid co-flow for an internally mixing twin-fluid Y-jet atomizer, and Tapia and Chavez (2002), which focuses on the internal flow pattern. In all studies except Song and Lee (1996), Andreussi et al. (1994), Mlkvik et al. (2015), Pacifico and Yanagihara (2014), and Tapia and Chavez (2002), the parameters such as injection conditions and atomizer geometry were taken as input while the spray dispersion was the reported output, but the intermediate process between the input and output of the nozzle has not been investigated in detail.

The present paper is the first to numerically model the multiphase flow through a twinfluid Y-jet atomizer as a function of the various operating conditions affecting it. In Nazeer

Volume 29, Issue 5, 2019 
et al. (2018) the authors have utilized the same computational model as in the present study and concluded on the influence of momentum ratio and gas to liquid ratio (GLR) on the internal flow development for a specific geometry. In the present study, the analysis extends to the effect of the geometric parameters of Y-jet atomizers. The presented results are used for validation of the developed model against relative literature findings for the pressure drop and the complex flow regime charts available in the literature for such nozzles.

\section{NUMERICAL METHOD}

The compressible Navier-Stokes equations are employed using the finite volume approximation; the volume of fluid (VOF) technique with a geometric reconstruction scheme is employed in ANSYS Fluent to model the gas-liquid interface. The phases in bulk are treated as noninterpenetrating continua; i.e., in most of the cells the volume fraction is either 1 or 0 . The interface is modeled as interpenetrating; i.e., the volume fraction in any cell could be between 0 and 1.

The interface is tracked with the following continuity equation. Here $\alpha_{q}$ is the volume fraction in the cell, $\rho_{q}$ is the density, and $\vec{V}_{q}$ is the velocity vector of the $q$ th phase.

$$
\frac{d}{d t}\left(\alpha_{q} \rho_{q}\right)+\nabla\left(\alpha_{q} \rho_{q} \vec{V}_{q}\right)=0 .
$$
ties.

The single set of momentum equations is shared among the phases based on mixture proper-

$$
\frac{d}{d t}(\rho \vec{V})+\nabla(\rho \vec{V} \vec{V})=-\nabla P+\nabla\left[\mu\left(\nabla \vec{V}+\nabla \vec{V}^{T}\right)\right]+\rho \vec{g}+\vec{T}_{\sigma}
$$

where density is defined as $\rho=\sum \alpha_{q} \rho_{q}$, viscosity as $\mu=\sum \mu_{q} \alpha_{q}$ and velocity as $\vec{V}=$ $(1 / \rho) \sum_{q=1}^{n} \alpha_{q} \rho_{q} \vec{V}_{q} \vec{T}_{\sigma}$ which is the volumetric force source term arising due to the surface tension. It is modeled by a continuum surface force model proposed by Brackbill et al. (1992). This model treats the surface tension as the pressure jump across the interface. The forces at the surface are expressed as volume forces using the divergence theorem.

$$
T_{\sigma}=\sum_{\text {pairs }, p, q} \sigma_{p, q} \frac{\alpha_{p} \rho_{p} k_{q} \nabla \alpha_{q}+\alpha_{q} \rho_{q} k_{p} \nabla \alpha_{p}}{(1 / 2)\left(\rho_{p}+\rho_{q}\right)} .
$$

The curvature of one surface is the negative of the other, $k_{p}=-k_{q}$, and the divergence of the volume fraction is the negative of the other, $\nabla \alpha_{p}=-\nabla \alpha_{q}$. This simplifies the equation to

$$
T_{\sigma}=\sigma_{p, q} \frac{\rho k_{p} \nabla \alpha_{p}}{(1 / 2)\left(\rho_{p}+\rho_{q}\right)} .
$$

The total energy of the flow is modeled by the following equation.

$$
\frac{d}{d t}(\rho E)+\nabla[\vec{V}(\rho E+P)]=\nabla\left(K_{\text {eff }} \nabla T+\overline{\bar{\tau}} \cdot \vec{V}\right) .
$$

Here $K_{\text {eff }}$ is the effective thermal conductivity, $\overline{\bar{\tau}}$ is the viscous stress tensor; the energy $E$ and temperature $T$ are mass-averaged variables.

$$
E=\frac{\sum_{q=1}^{n} \alpha_{q} \rho_{q} E_{q}}{\sum_{q=1}^{n} \alpha_{q} \rho_{q}}
$$

$E_{q}$ is the internal energy of each phase; both phases share the same temperature. 
The scale resolving technique is adopted to resolve larger eddies through the wall modeled LES (WMLES) model. As the Reynolds number increases and the boundary layer becomes thinner, the size of important energy-bearing eddies decreases. In LES, the important energy-bearing eddies must be resolved; thus the cost of maintaining grid resolution becomes prohibitive. In this model larger eddies are resolved while eddies in thinner near-wall regions-in which the wall distance is much smaller than boundary-layer thickness but is still potentially very large in wall units (Piomelli and Balaras, 2002) - is modeled with RANS, hence considerably reducing the computational cost. A Gaussian filter is applied to filter out eddies based on length scale $\Delta$ (Shur et al., 2008).

$$
\begin{gathered}
\bar{\emptyset}(x, t)=\int_{D} \emptyset\left(x^{\prime}, t\right) G\left(x, x^{\prime}, \Delta\right) d x^{\prime}, \\
\Delta=\min \left[\max \left(C_{w} . d s_{w} ; C_{w} \cdot h_{\max }, h_{\mathrm{wn}}\right) ; h_{\max }\right] .
\end{gathered}
$$

$h_{\max }=$ maximum edge length; $h_{\mathrm{wn}}=$ grid step in wall-normal direction; $C_{w}=0.15, d_{w}=$ distance from wall.

After putting the filtered-out variables in the Navier-Stokes equation and rearranging the terms, it could be expressed as

$$
\frac{\left(\partial \bar{V}_{i}\right)}{\partial t}+\frac{\partial\left(p \bar{V}_{i} \bar{V}_{j}\right)}{\partial x_{j}}=-\frac{\partial \bar{P}}{\partial x_{i}}+\frac{\partial\left(\bar{\tau}_{i j}+\tau_{i j}^{s}\right)}{\partial x_{j}} .
$$

This equation could be resolved except for subgrid-scale stress $\tau_{i j}^{s}$. It can be expressed by the Boussinesq hypothesis (Hinze, 1975) as

$$
\tau_{i j}^{s}-\frac{1}{3} \tau_{k k} \delta_{i j}=-2 \mu_{t} S_{i j}
$$

The subgrid-scale eddy viscosity is modeled with the Smagorinsky SGS model (Smagorinsky, 1963) with van Driest damping (Van Driest, 1956), and the mixing length model as

$$
v_{t}=\min \left[\left(k d s_{w}\right)^{2},\left(C_{\mathrm{smag}} \Delta\right)^{2}\right]\left[1-\exp \left[-\left(y^{+} / 25\right)^{3}\right]\right]|S-\Omega| .
$$

$C_{\text {smag }}=0.2$ is the Smagorinsky constant, as established by Shur et al. (1999), $\Omega$ is the vorticity, $S$ is the magnitude of the strain tensor, $k=0.41$ is the von Kármán constant.

\section{TEST CASE SIMULATED}

Seven different Y-jet atomizers are used for the parametric analysis. Air and water are used as working fluids at atmospheric conditions. The geometries are constructed in ANSYS Design Modeler according to the design criteria of Mullinger and Chigier (1974); the same design criteria were also adopted by Pacifico and Yanagihara (2014) for the experimental study on pressure drop within internally mixing twin-fluid Y-jet atomizers. The geometries are meshed in ANSYS Meshing tool. The grids are polyhedral with the number of elements ranging between 15 and 17.3 million. The $\mathrm{Y}^{+}$values are in the range of $0.72-0.94$. The schematic of the nozzle studied is shown in Fig. 1. Table 1 shows the geometrical parameters of all the seven atomizers. All the pressure points as shown in Fig. 1; i.e., $P_{a}, P_{w}, P_{m}, P_{1}$, and $P_{2}$ are obtained from the numerical solutions, where $P_{m}$ is the mixing point pressure, $P_{a}$ is the gas (air) inlet pressure, $P_{w}$ is the liquid (water) inlet pressure, $P_{1}$ is the pressure at the middle point along the length of the mixing

Volume 29, Issue 5, 2019 


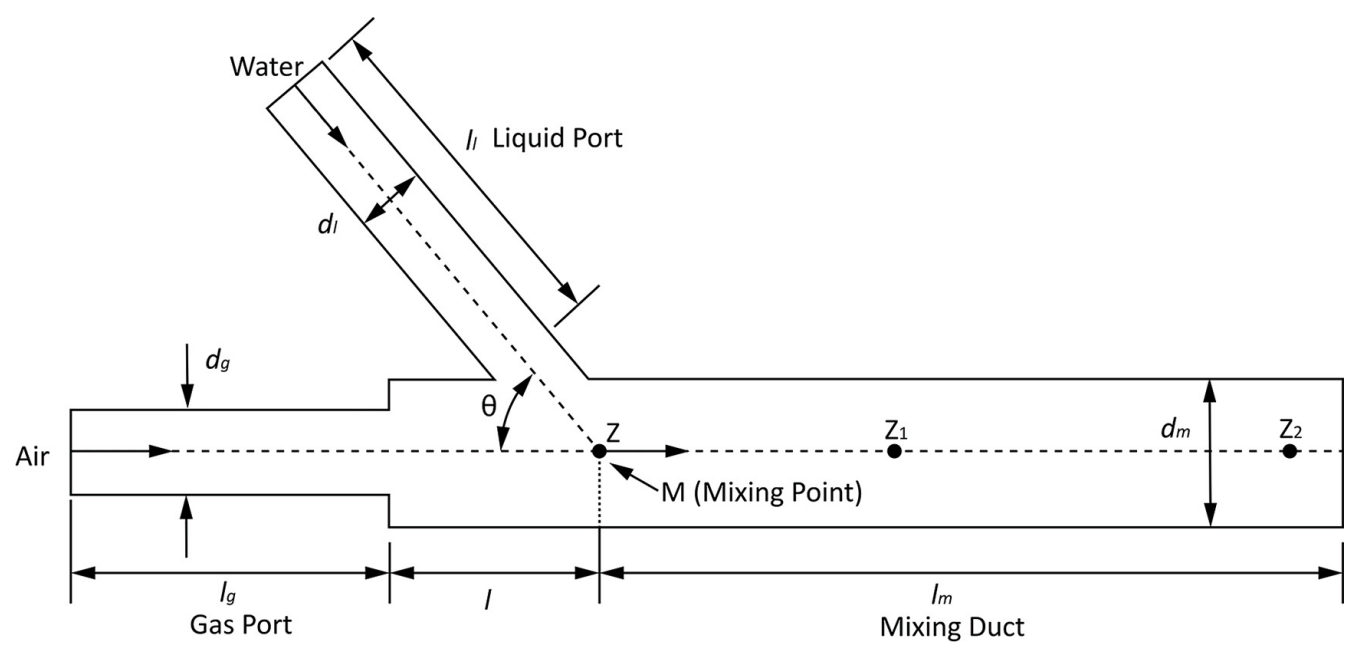

FIG. 1: Schematic of the nozzle used for the parametric study

TABLE 1: Geometric values for the parameters shown in Fig. 1

\begin{tabular}{|c|c|c|c|c|c|c|c|c|c|c|}
\hline Nozzle & $\begin{array}{c}\boldsymbol{l}_{\boldsymbol{g}} \\
(\mathbf{m m})\end{array}$ & $\begin{array}{c}\boldsymbol{l} \\
(\mathbf{m m})\end{array}$ & $\begin{array}{c}\boldsymbol{l}_{\boldsymbol{m}} \\
(\mathbf{m m})\end{array}$ & $\begin{array}{c}\boldsymbol{d}_{\boldsymbol{g}} \\
(\mathbf{m m})\end{array}$ & $\begin{array}{c}\boldsymbol{d}_{\boldsymbol{m}} \\
(\mathbf{m m})\end{array}$ & $\boldsymbol{\theta}$ & $\boldsymbol{l}_{\boldsymbol{m}} / \boldsymbol{d}_{\boldsymbol{m}}$ & $\boldsymbol{d}_{\boldsymbol{m}} / \boldsymbol{d}_{\boldsymbol{g}}$ & $\begin{array}{c}\boldsymbol{z}_{\mathbf{1}} \\
(\mathbf{m m})\end{array}$ & $\begin{array}{c}\boldsymbol{z}_{\mathbf{2}} \\
(\mathbf{m m})\end{array}$ \\
\hline $\mathrm{A}$ & 50 & 14.4 & 50 & 5.5 & 10 & $57^{\circ}$ & 5.00 & 1.82 & 25 & 42.5 \\
$\mathrm{~B}$ & 50 & 14.4 & 50 & 6.0 & 10 & $57^{\circ}$ & 5.00 & 1.67 & 25 & 42.5 \\
$\mathrm{C}$ & 50 & 14.4 & 50 & 6.0 & 12 & $57^{\circ}$ & 4.17 & 2.00 & 25 & 42.5 \\
$\mathrm{D}$ & 50 & 16.2 & 50 & 6.0 & 10 & $45^{\circ}$ & 5.00 & 1.67 & 25 & 42.5 \\
$\mathrm{E}$ & 50 & 13.0 & 50 & 6.0 & 10 & $70^{\circ}$ & 5.00 & 1.67 & 25 & 42.5 \\
$\mathrm{~F}$ & 50 & 14.4 & 35 & 6.0 & 10 & $57^{\circ}$ & 3.50 & 1.67 & 17.5 & 27.5 \\
$\mathrm{G}$ & 50 & 14.4 & 100 & 6.0 & 10 & $57^{\circ}$ & 10.00 & 1.67 & 50 & 92.5 \\
\hline
\end{tabular}

port, and $P_{2}$ is the pressure near the exit of the mixing port. Mass flow boundary conditions are employed at the gas port and liquid port inlets while the pressure outlet boundary condition is employed at the exit of the mixing duct.

In order to keep geometrical and operational similarity with the work of Pacifico and Yanagihara (2014), nondimensionless numbers, i.e., Weber numbers, are calculated for the flow in the mixing duct. Weber numbers used by Pacifico and Yanagihara (2014) are in the range of 500-42,500, while the Weber numbers used in this work are also nearly in the same range, i.e., between 600 and 45,000. Weber numbers are calculated with the following formula:

$$
\mathrm{We}=\frac{\rho_{a, m} V_{r}^{2} d_{m}}{\sigma}
$$

where $\rho_{a, m}$ is the density of the air at the mixing point, $V_{r}$ is the relative velocity between the air and water, $d_{m}$ is the mixing port diameter. The mass flow rate of air and water were also applied almost in the same range as stated in the literature. The mass flow rate of the air was in the range $0.008-0.091 \mathrm{~kg} / \mathrm{s}$ while the mass flow rate of the water was in the range $0.075-0.78 \mathrm{~kg} / \mathrm{s}$.

For each of the seven nozzles a total of 11 simulations were performed. Gas to liquid mass flow rate ratio (GLR) was varied from 0.01 to 0.9 . The main geometrical parameters studied 
include the angle $(\theta)$ between the liquid port and the mixing port, mixing port length to diameter ratio $\left(l_{m} / d_{m}\right)$, and mixing port diameter to gas port diameter ratio $\left(d_{m} / d_{g}\right)$. The values used for the aforementioned geometrical parameters are in the following ranges: $\pi / 4 \leq \theta \leq$ $7 \pi / 18\left(45^{\circ}-70^{\circ}\right), 3.5 \leq l_{m} / d_{m} \leq 10$, and $1.67 \leq d_{m} / d_{g} \leq 2$. The following sets of atomizers were used for each of the parametric study: nozzles B, D, and E are used for the parametric study of $\theta ; \mathrm{B}, \mathrm{F}$, and $\mathrm{G}$ for $l_{m} / d_{m}$; and $\mathrm{A}, \mathrm{B}$, and $\mathrm{C}$ for $d_{m} / d_{g}$. These values are shown in Table 1 for each nozzle.

\section{RESULTS AND DISCUSSION}

Figure 2(a) shows contours of the volume fraction of water and air. At first it could be seen that the gas-liquid flow is annular, with the liquid film formed on the inner wall of the mixing duct. As the high-speed air jet impinges on the liquid jet, it creates a disturbance on the surface of the liquid column, leading to creation of a wavy structure in the liquid column/film. This may lead
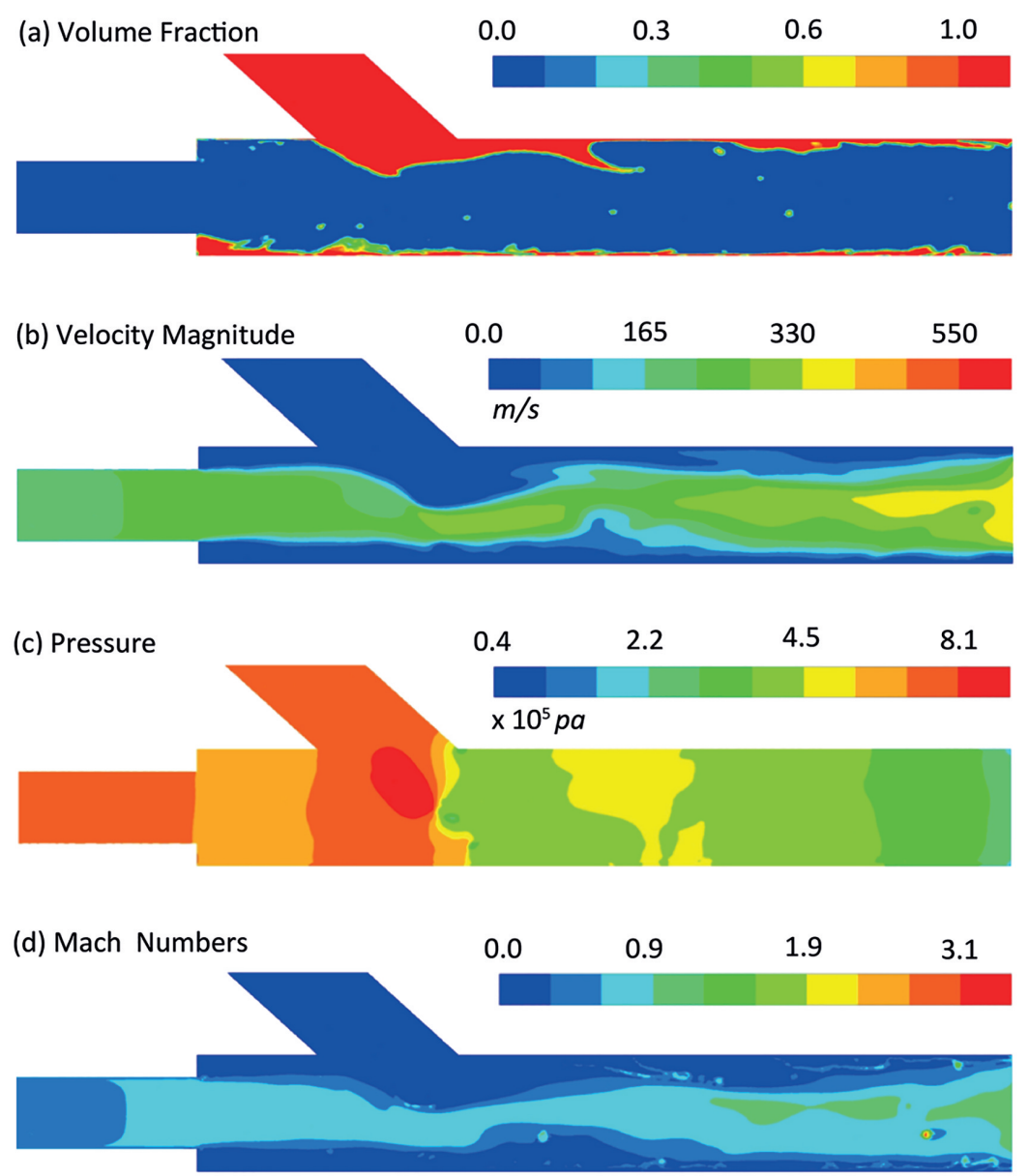

FIG. 2: Flow field for the nozzle D with GLR $=0.29$ : (a) volume fraction contours, (b) velocity contour, (c) pressure contour, and (d) Mach number contour

Volume 29, Issue 5, 2019 
to inception of the primary breakup of the liquid jet within the nozzle. The liquid film formed just downstream of the gas port in the mixing duct is because of the recirculation of the air due to its expansion from the gas port into the mixing duct. The expansion of the air is limited by the higher pressure of the liquid jet [Fig. 2(c)]. This leads to recirculation of the air in the premixing zone of the mixing duct. Figure 3(a) shows the recirculating velocity vectors in the recirculating zone. Figure 3(b) is the schematic illustration of the reverse flow and liquid film formation in the premixed zone. A portion of the water stream flows backward in the form of a film towards the upstream by the recirculating air flow. When the reverse film flow meets the main air stream at the exit of the gas port, it disintegrates into droplets and flows downstream along the core, as illustrated in Fig. 3(b). Figure 2(b) shows the contour of the velocity. The air jet accelerates as it expands from the gas port into the mixing duct. It further accelerates as it bypasses the relatively slow moving liquid jet emanating from the liquid port. It then slightly decelerates while aligning with the liquid film before it rapidly accelerates towards the exit of the nozzle. Figure 2(c) shows the contour of the pressure. The higher pressure around the area of air impingement on the liquid column is due to the increase in static pressure because of dynamic pressure of the air jet. Figure 2(d) shows the contour of the Mach number of the forming multiphase flow. The speed of the sound is much lower in the gas-liquid mixture than in either the pure liquid or gas component. For example, it is $1480 \mathrm{~m} / \mathrm{s}$ in water and $340 \mathrm{~m} / \mathrm{s}$ in air, but in the air-water mixture it can fall to $20 \mathrm{~m} / \mathrm{s}$ (McWilliam and Duggins, 1969). This process occurs because the two-phase system has the effective density of the liquid but the compressibility of the gas (Kieffer, 1977) (refer to Appendix A for further details). In Fig. 2(d) it can be seen that in the mixing duct, Mach numbers are higher at the gas-liquid interface and around the exit of the nozzle. Although the instantaneous Mach numbers could be higher than 1, there is no evidence of flow choking in the mixing duct. Pacifico and Yanagihara (2014) also reached the same conclusion about gas-liquid multiphase flow in the mixing duct of a Y-jet atomizer.

(a)
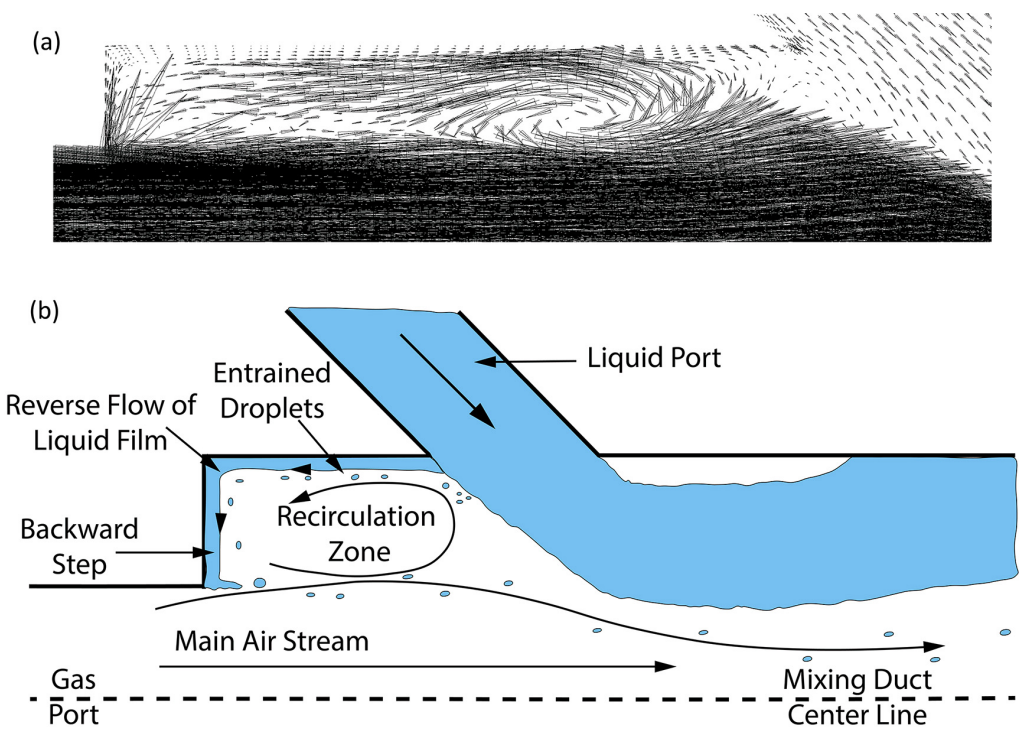

FIG. 3: (a) recirculating velocity vectors in recirculation zone, (b) schematic illustration of recirculating air flow and reverse film formation 
Figures 4 and 5 depict the plots of the ratios of mixing point pressure to air inlet pressure $\left(P_{m} / P_{a}\right)$ and water inlet pressure to air inlet pressure $\left(P_{w} / P_{a}\right)$ against the GLR ratios, respectively. At first, in qualitative terms the results of all the nozzles are similar; i.e., with increasing GLR both ratios decrease. Increase in GLR is attributed to either increase in air mass flow rate or decrease in water mass flow rate. This, in turn, induces the air flow momentum to have larger influence on the mixing process and particularly on mixing point pressure. On the other hand,

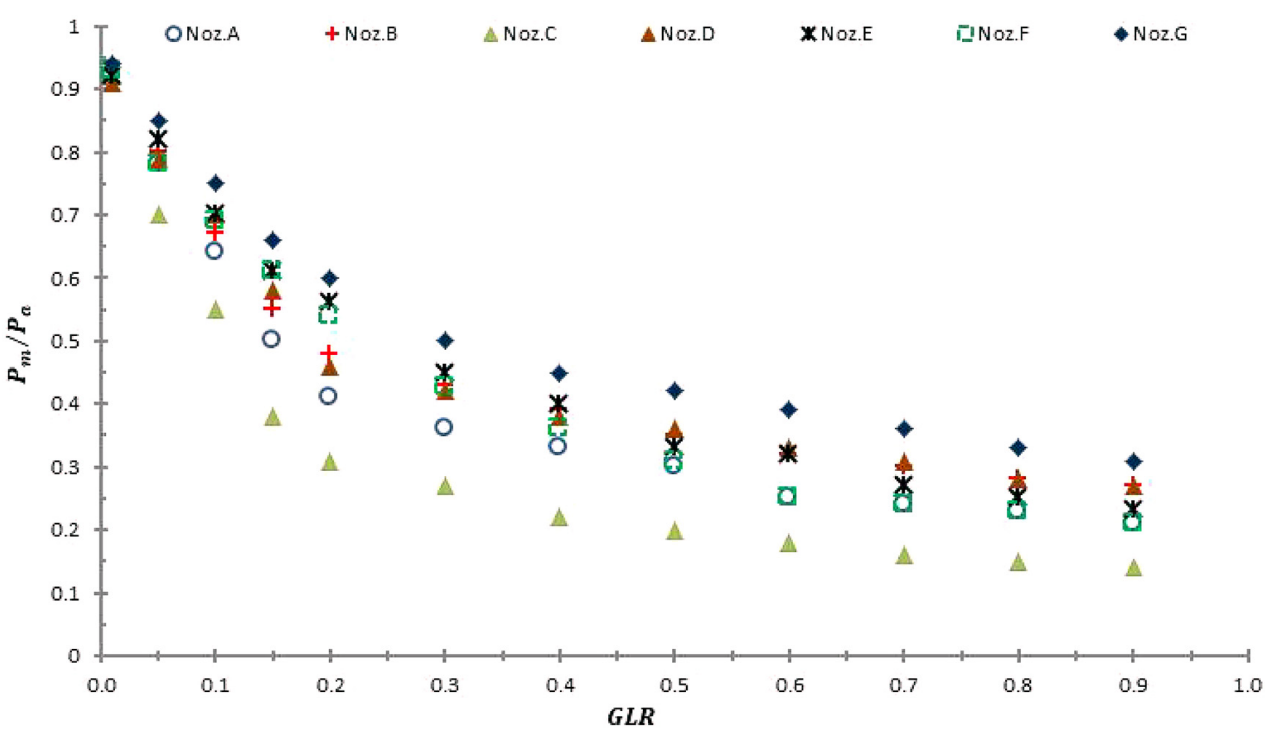

FIG. 4: Plot of mixing point pressure to air inlet pressure ratio against gas to liquid mass flow rate ratio

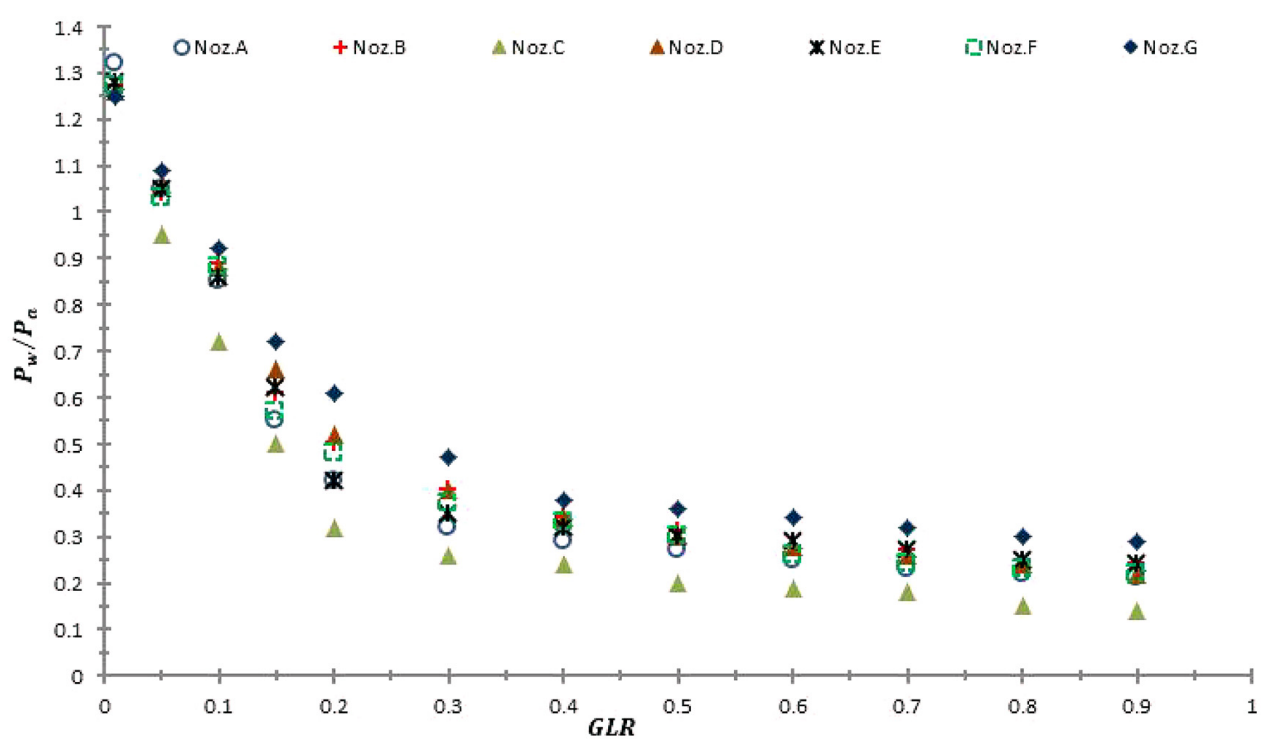

FIG. 5: Plot of water inlet pressure to air inlet pressure ratio against gas to liquid mass flow rate ratio

Volume 29, Issue 5, 2019 
water flow determines the back pressure for the air jet expanding from the gas port into the mixing port. This behavior is inherent to any compressible flow expansion. It could be seen that the rate of decrease of the $P_{w} / P_{a}$ ratio is higher than that of the $P_{m} / P_{a}$ ratio. This is because the water mass flow rate limits the expansion of the gas stream and hence leads to the conclusion that $P_{m}$, among the others, are controlled by the water inlet pressure.

It could be seen from the plots that except for GLR $=2$, there is virtually no difference among the results obtained for the angle between the mixing port and the liquid port as the function of GLR (nozzles B, D, and E). This concludes that the angle does not have a significant effect on the mixing point pressure. Ferreira et al. (2009b) reached the same conclusion for the effect of angle on the Sauter mean diameter (SMD) of the droplets produced by a twin-fluid atomizer with the mixing chamber. This leads to the hypothesis that the mixing point pressure does plays a role in the performance of an internally mixing twin-fluid atomizer. Regarding the influence of the $l_{m} / d_{m}$ ratio on the mixing point pressure (nozzles $\mathrm{B}, \mathrm{F}$, and $\mathrm{G}$ ), it could be noticed that the mixing point pressure increases with the increasing $l_{m} / d_{m}$ ratio. It should be noted that $d_{m}$ is constant for all three nozzles; hence the mixing point pressure increases with increasing mixing port length. This behavior is explained as being due to the smoother drop of the pressure for the large values of $l_{m}$. Since the outlet pressure is the same for all the nozzles (i.e., atmospheric pressure), the nozzle with the higher value of of $l_{m}$ has a higher $P_{m}$. Mullinger and Chigier (1974) reported that droplet size decreases for the nozzle with a longer mixing port, while in contrast, Song and Lee (1994) reported that droplet size decreases with shorter mixing port length. This contradiction was later clarified by Song and Lee (1996). They reported that for relatively small liquid mass flow rate and high gas flow rate, the droplets generated by the nozzle with a shorter mixing port are generally smaller than the droplets generated by the nozzle with a longer mixing port, whereas for relatively large liquid mass flow rate and smaller gas flow rate, the droplets produced by the nozzle with longer mixing port are comparable or even slightly smaller than the drops produced by a nozzle with a smaller mixing port length. This discrepancy could be explained with the work of Lefebvre (1992). At low liquid mass flow rate and high gas mass flow rate, for the nozzle with a shorter mixing port, there is not enough time for the wavy structure to be formed in the liquid core/film; thus the liquid and gas do not align while co-flowing. Hence, gas impinges at an angle on the liquid sheets outside the nozzle, leading to vigorous breakup of liquid sheets into small fragments; this process was termed "prompt atomization." If one observes carefully the data points for nozzles F and G in Fig. 2, it can be seen that for the small values of GLR (say, GLR $<3$ ) there is not much difference between the $P_{m} / P_{a}$ ratio for the nozzle with a long mixing port (nozzle $\mathrm{G}$ ) and the nozzle with a short mixing port (nozzle F). For the values of GLR $\geq 3$ this difference increases. Smaller values of GLR mean lower gas mass flow rate or relatively higher liquid flow rate and a large value of GLR means vice versa. This difference in pressure drop coincides with the performance of the nozzles as observed by Song and Lee (1996). Finally, comparing the data points of the nozzles A, B, and C, it is evident from the plot in Fig. 2 that the $d_{m} / d_{g}$ ratio has the most significant effect on the mixing point pressure among all the geometrical parameters studied. The higher the value of the $d_{m} / d_{g}$ ratio, the higher is the value of the pressure reduction between the gas inlet pressure and mixing point pressure (nozzle $\mathrm{C}$ ). Particularly in the range $0.01<\mathrm{ALR}<0.4$, the influence of $d_{m} / d_{g}$ is more significant, indicating that the gas pressure drop in this range is more when the $d_{m} / d_{g}$ ratio is incremented. Similarly, $P_{w} / P_{a}$ has the same behavior as a function of GLR as that of $P_{m} / P_{a}$ for the geometrical parameters studied (Fig. 5).

Figure 6 depicts the ratio of air mass flow rate to the maximum air mass flow rate (for $\mathrm{Ma}=$ 1 at the throat between gas port and mixing port) as a function of pressure ratio $\left(P_{m} / P_{a}\right)$. In the 


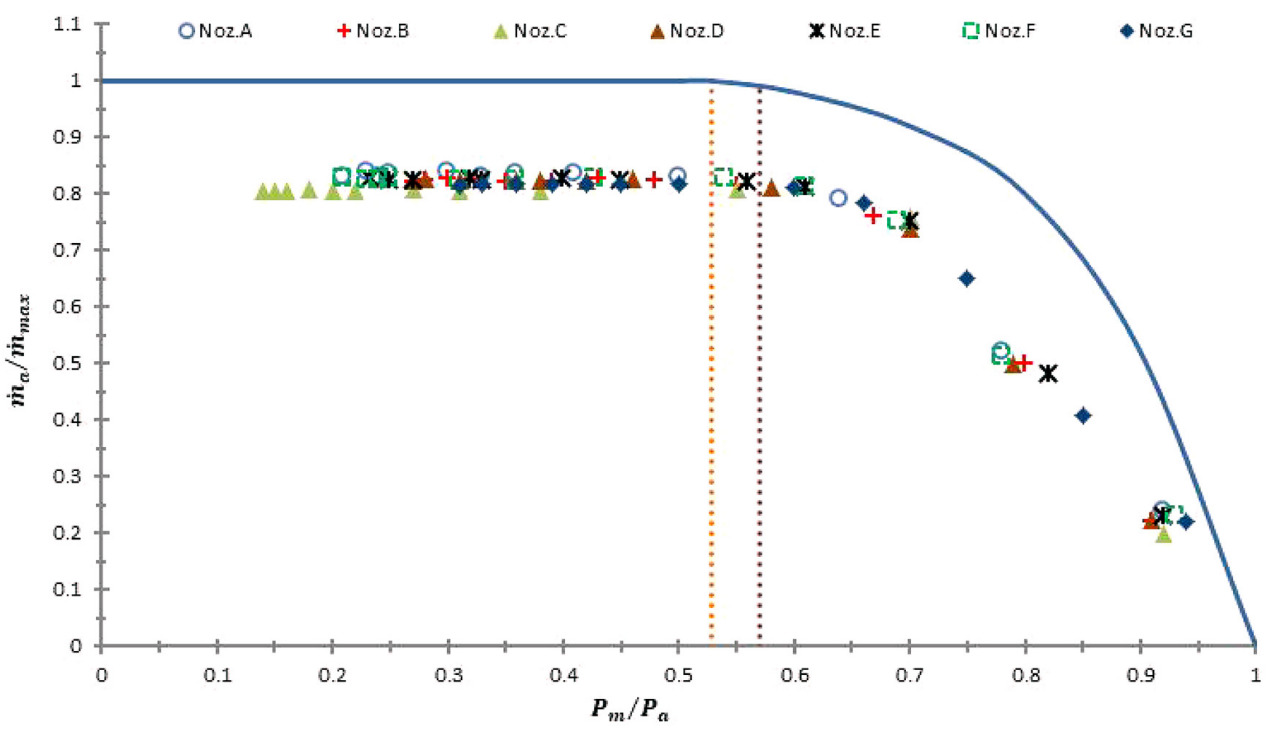

FIG. 6: Plot of the ratio of air mass flow rate to maximum air mass flow rate through gas port against pressure ratio. The continuous blue line is the curve for isentropic flow through a converging-diverging nozzle.

same figure, the curve for isentropic flow through the converging-diverging nozzle is also plotted (continuous line). The flow in the Y-jet atomizers from the gas port to the mixing port is similar to the flow through the converging-diverging nozzle where $d_{g}$ acts as a nozzle throat and $P_{m}$ (mixing point pressure) as the back pressure. The deviation of the data points from the isentropic prediction line is due to the irreversibility of the sudden expansion of the air and the presence of liquid around the mixing point. This behavior is also observed by Ferreira et al. (2009b). The orange dashed line shows the pressure ratio $\left(P_{m} / P_{a}=0.5283\right)$ at which isentropic compressible flow through a converging-diverging nozzle is choked. The red dashed line $\left(P_{m} / P_{a}=0.565\right)$ shows the deviation of the shocked region from the isentropic compressible flow. Ferreira et al. (2009a,b) explained that the presence of water in the mixing port restricts the air flow; the liquid mass flow rate changes the value of the gas mass flow rate at which flow is choked for the same geometric expansion $\left(d_{m} / d_{g}\right)$. However, the choked condition always occurs at the exit of the gas port, not downstream of this point (Pacifico and Yanagihara, 2014; Ferreria et al., 2009). Ferreira et al. (2009) observed that the smallest SMDs (Sauter mean diameter) are produced at choked conditions. This is an important operational parameter for internally mixing twin-fluid atomizers. However, in the case of thermal power plants, when operating at choked conditions, a large amount of steam flow at high velocity is supplied to the combustion chamber. The intense interaction with the turbulence field induces high strain rates in the flame front leading to local flame extinction; this elongation of the flame might end up in contact with the boiler wall. In these cases, the reaction times become larger than the mixing time, leading to formation of soot (Warnatz et al., 2001). Secondly, large amount of water introduced into the flame cools down the reaction zone leading to a decrease in local temperature that might lead to flame extinction and prevent reignition of the mixture.

In order to compare all the parameters analyzed in Figs. 4 and 5 with the empirical correlations for $P_{m} / P_{a}$ and $P_{w} / P_{a}$ proposed by Pacifico and Yanagihara (2014), data points of all the

Volume 29, Issue 5, 2019 
nozzles A-G and the correlations of $P_{m} / P_{a}$ and $P_{w} / P_{a}$ are plotted in Figs. 7 and 8, respectively. The correlations are

$$
\begin{aligned}
& \frac{P_{m}}{P_{a}}=0.169+0.81 \exp \left[-0.675 \theta^{-0.22}\left(\frac{l_{m}}{d_{m}}\right)^{-0.38}\left(\frac{d_{m}}{d_{g}}\right)^{4} \mathrm{GLR}^{0.87}\right], \\
& \frac{P_{w}}{P_{a}}=0.161+1.06 \exp \left[-1.08 \theta^{-0.11}\left(\frac{l_{m}}{d_{m}}\right)^{-0.25}\left(\frac{d_{m}}{d_{g}}\right)^{3} \mathrm{GLR}^{0.82}\right] .
\end{aligned}
$$

These correlations, shown in Eqs. (13) and (14), are valid for the ranges $0 \leq$ GLR $\leq 1$, $3.5 \leq l_{m} / d_{m} \leq 10,1.67 \leq d_{m} / d_{g} \leq 2$, and $45^{\circ}<\theta<70^{\circ}$. In these correlations, $\theta$ must be in radians $(\pi / 4<\theta<7 \pi / 18)$. It can be seen in Figs. 7 and 8 that there is good agreement between the proposed correlations and the current simulation results. An important operational parameter is the condition of critical gas flow. For the present numerical study it is $P_{m} / P_{a}<0.565$; this is obtained when $-0.675 \theta^{-0.22}\left(l_{m} / d_{m}\right)^{-0.38}\left(d_{m} / d_{g}\right)^{4} \mathrm{GLR}^{0.87}>1.05$.

Figure 9 shows the plot of the data points obtained from the simulations and the plot of the correlation $\left(P(z) / P_{a}\right)$ proposed by Pacifico and Yanagihara (2014) for the pressure drop along the length of the mixing chamber. Numerical results agree well with the proposed correlation. Following is the correlation:

$$
\begin{aligned}
\frac{P(z)}{P_{a}} & =0.172+0.732 \exp \left[-0.371 \theta^{-0.203}\left(\frac{l_{m}}{d_{m}}\right)^{-0.422}\left(\frac{d_{m}}{d_{g}}\right)^{5.152} \mathrm{GLR}^{0.988}\right. \\
& \left.-1.286\left(\frac{z}{l_{m}}\right)^{1.251}\right]
\end{aligned}
$$

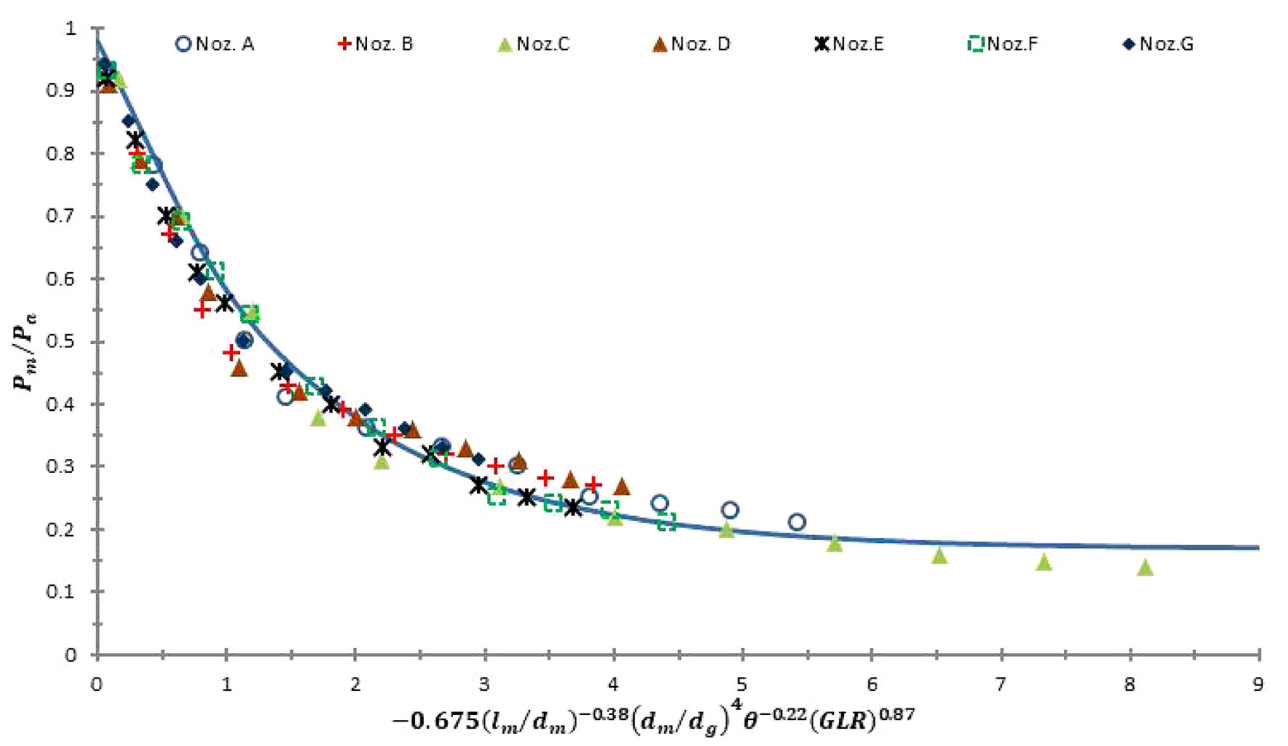

FIG. 7: Comparison of numerical data points against empirical correlation [Eq. (13)] for the mixing point pressure to the air inlet pressure ratio proposed by Pacifico and Yanagihara (2014) 


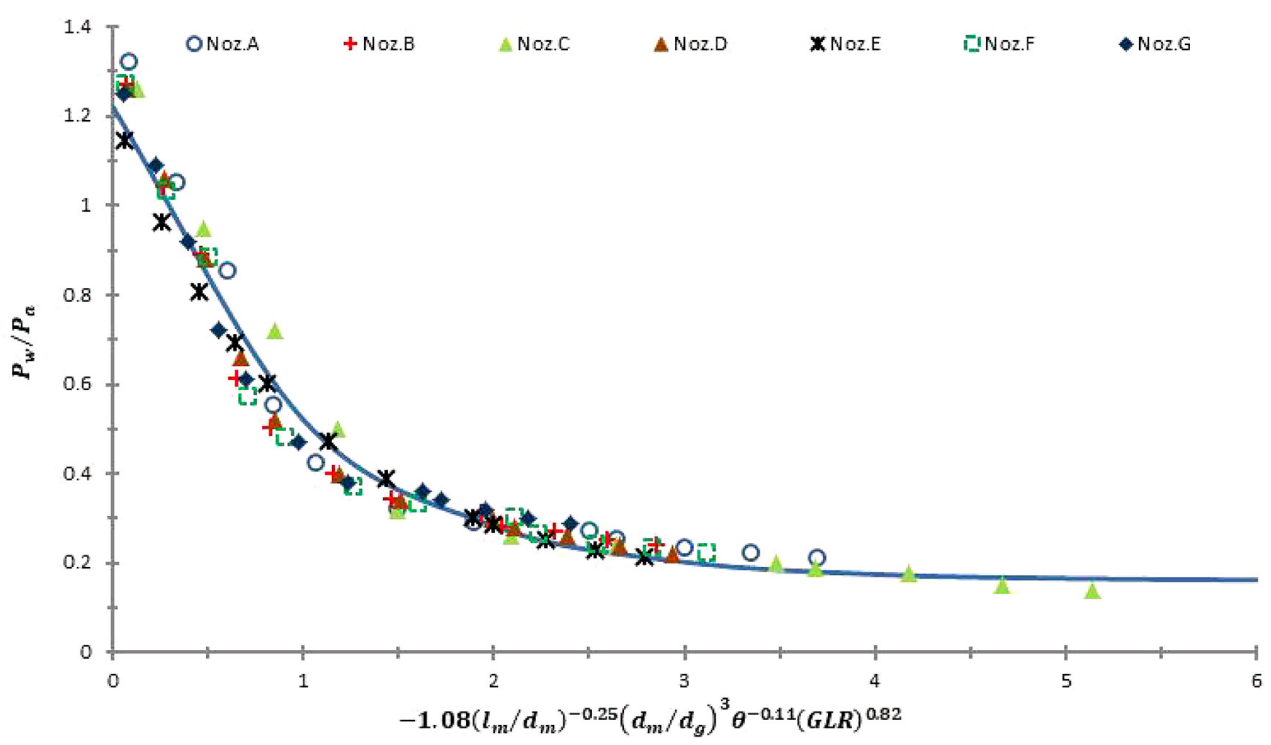

FIG. 8: Comparison of numerical data points against empirical correlation [Eq. (14)] for the water inlet pressure to the air inlet pressure ratio proposed by Pacifico and Yanagihara (2014)

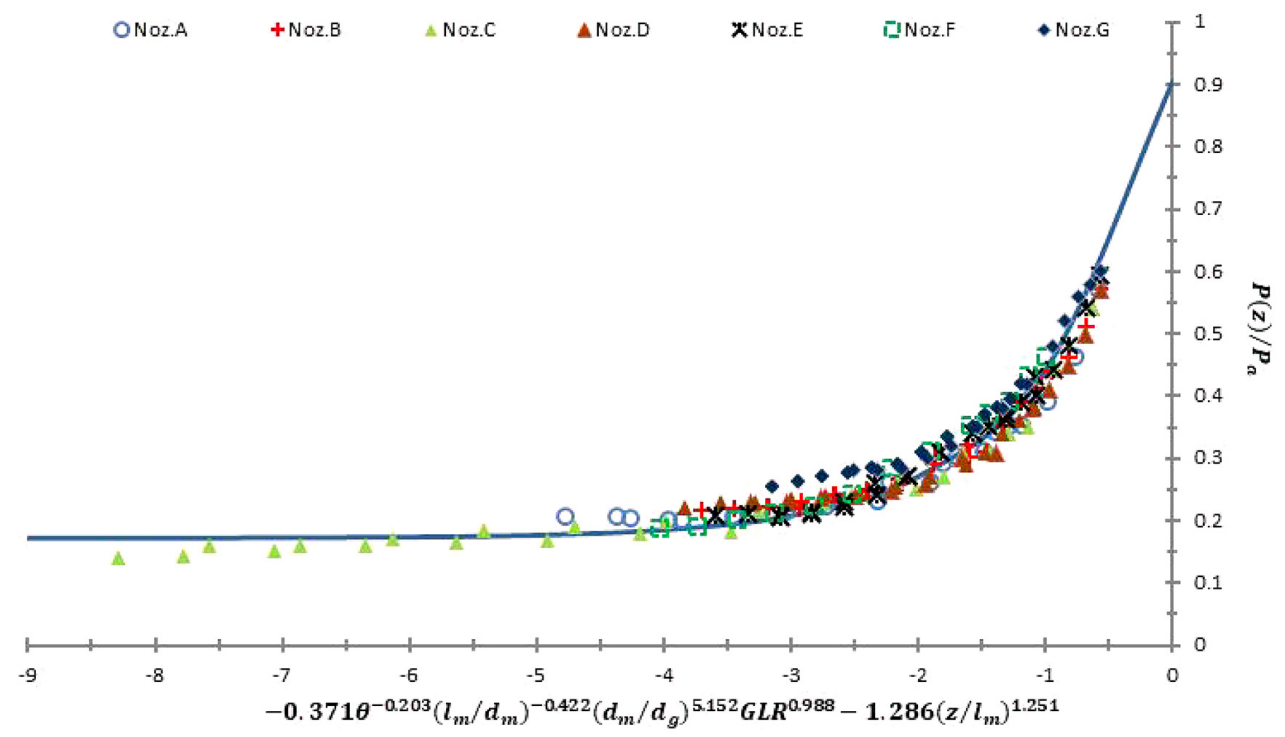

FIG. 9: Comparison of numerical data points against the empirical correlation [Eq. (15)] based on GLR for the pressure drop along the length of the mixing port proposed by Pacifico and Yanagihara (2014)

Another parameter used for the analysis of an internally mixing twin-fluid Y-jet atomizer is the "momentum ratio" $(\varphi)$; this is the ratio of the momentum of the liquid jet going into the mixing port and the momentum of the auxiliary fluid (air or steam). This ratio was first used by De Michele et al. (1991) for the analysis of twin-fluid Y-jet atomizers. It was used in previous studies by Song and Lee (1996), Andreussi et al. (1992), Mlkvik et al. (2015), and Nazeer et al.

Volume 29, Issue 5, 2019 
(2018). Momentum ratio is defined as

$$
\varphi=\frac{G_{l}^{2} d_{l}^{2} \rho_{a, m} \sin \theta}{G_{g, m}^{2} d_{m}^{2} \rho_{w}},
$$

where $G_{l}$ is the liquid mass velocity, $G_{g, m}$ is the gas mass velocity based on mixing port cross sectional area, and $\rho_{a, m}$ is the gas density at the mixing point.

The correlation based on momentum ratio for the pressure drop along the length of the mixing chamber $\left(P(z) / P_{a}\right)$ proposed by Pacifico and Yanagihara is plotted in Fig. 10. Numerical data points are also plotted in the same figure. Again the results agree well with the proposed correlation. Following is the correlation:

$$
\begin{aligned}
\frac{P(z)}{P_{a}} & =0.172+0.764 \exp \left[-0.048 \theta^{0.072}\left(\frac{l_{m}}{d_{m}}\right)^{-0.309}\left(\frac{d_{m}}{d_{a}}\right)^{4.536} \varphi^{-0.371}\right. \\
& \left.-1.286\left(\frac{z}{l_{m}}\right)^{1.251}\right] .
\end{aligned}
$$

Figure 11 shows the contours of the volume fraction for nozzle "D" for the three different GLR ratios. When the GLR ratio is low [0.01, Fig. 11(a)], the flow seems to be somewhat transitional between froth/churn-turbulent flow and annular-wispy flow. As the GLR increases [0.1, Fig. 11(b)] the flow is clearly in the wispy-annular regime with an annular liquid film surrounding the gas core comprising of dispersed droplets and ligaments. As the GLR increases further [0.3, Fig. 11(c)], the flow is clearly in the annular flow regime, with a wavy annular film around the gaseous core. These changes in the flow patterns occurring upstream of the discharge orifice greatly affect the atomization and spray formation downstream of the nozzle exit. For instance,

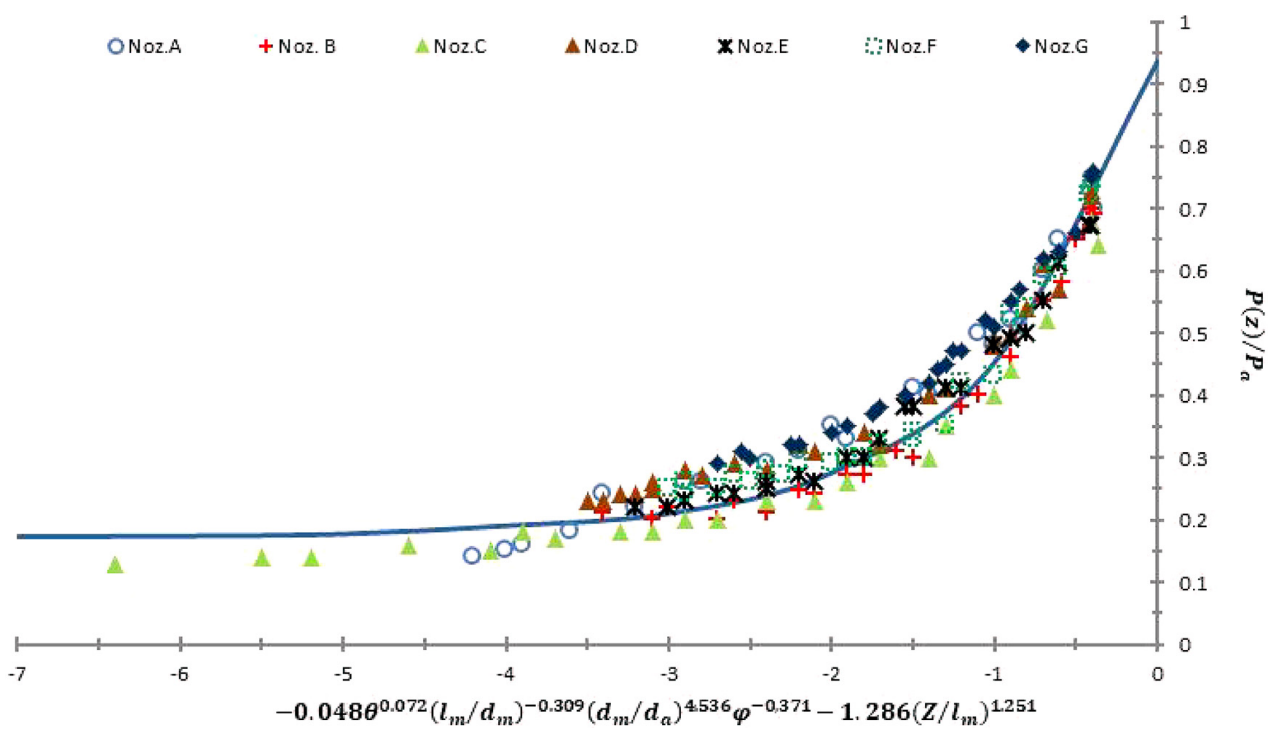

FIG. 10: Comparison of numerical data points against the empirical correlation [Eq. (17)] based on momentum ratio $(\varphi)$ for the pressure drop along the length of the mixing port proposed by Pacifico and Yanagihara (2014) 


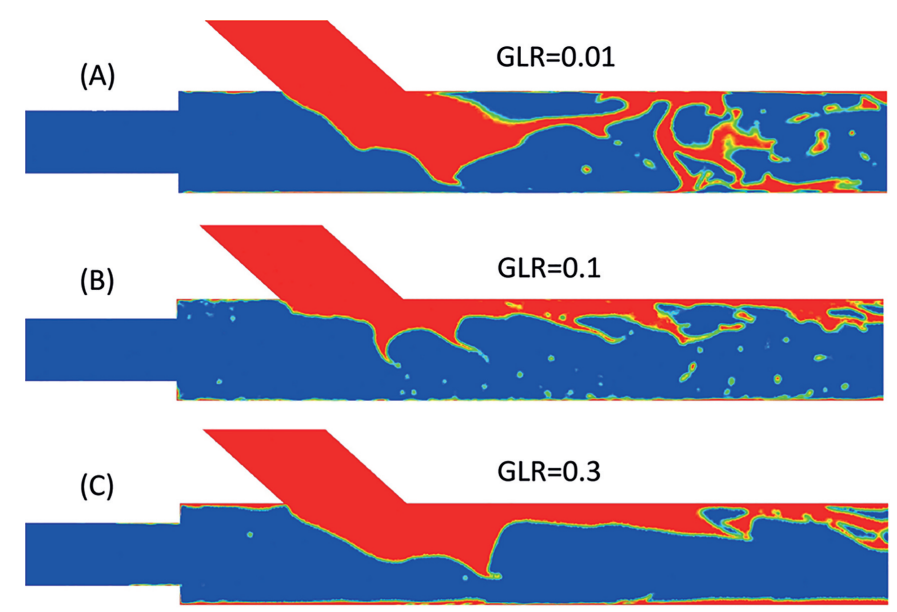

FIG. 11: Contour of volume fraction of air-water multiphase flow at three different GLRs

when the flow within the nozzle is churn-turbulent flow, the spray formed is not stable; while, if the flow pattern is annular, the nozzle operates as a plain-jet air-blast atomizer, comprising a central core of high-velocity gas surrounded by an annular film of liquid. The relative velocity between the gas and liquid ensures good atomization.

In order to verify the flow regimes, the data points of all the nozzles were plotted on the vertical pipe flow regime map proposed by Hewitt and Roberts (1969) and Oshinowo and Charles (1974). There are of course, some significant differences between the "classical" flow regimes examined in the literature and the types of flow patterns that can arise in practical atomizers. The former is confined to fully developed flow in long, constant cross-section pipes; whereas the flow in the atomizer is of short length and the flow is transient in nature, roughly equivalent to the flow at the inlet of the long pipes. Moreover, the flow in the atomizer is accelerating from the mixing duct to the exit orifice. However, despite these aforementioned differences in the flow nature, the flow patterns that are normally associated with the two-phase flow in long pipes can usefully contribute to the better understanding of the flow regimes in the atomizers (Chin and Lefebvre, 1993).

Figure 12 shows the Hewitt and Roberts multiphase flow map (Hewitt and Roberts, 1969). This map has been found to fit a reasonably large range of fluids and is of particular interest in the high-mass flux region (Hawkes et al., 2000). The coordinates represent the momentum fluxes; the ordinate represents the air momentum flux while the abscissa represents the water momentum flux. $J_{w}$ and $J_{a}$ are superficial velocities of water and air, respectively. The data points for all seven nozzles are also plotted on this map. It can be seen that the main flow patterns are annular and wispy annular. GLR ratio decreases with increase in water momentum flux; then according to this map, for small values of GLR, the wispy annular is the main flow pattern while for larger values of GLR, the annular flow is the main flow pattern. This result matches with the flow pattern observed within the nozzle [Figs. 11(b) and 11(c)]. However, there is a small discrepancy between the results; at the lowest value of GLR in the study (0.01) flow seems to be transitional between the froth/churn turbulent flow and the wispy-annular flow [Fig. 11(a)], while, according to the map, it should be wispy-annular flow. Nevertheless, in industrial boilers the GLR ratio is usually in the range $0.1<$ GLR $<0.3$. Flow is wispy annular at the lower end of this range and annular at the higher end of the range.

Volume 29, Issue 5, 2019 


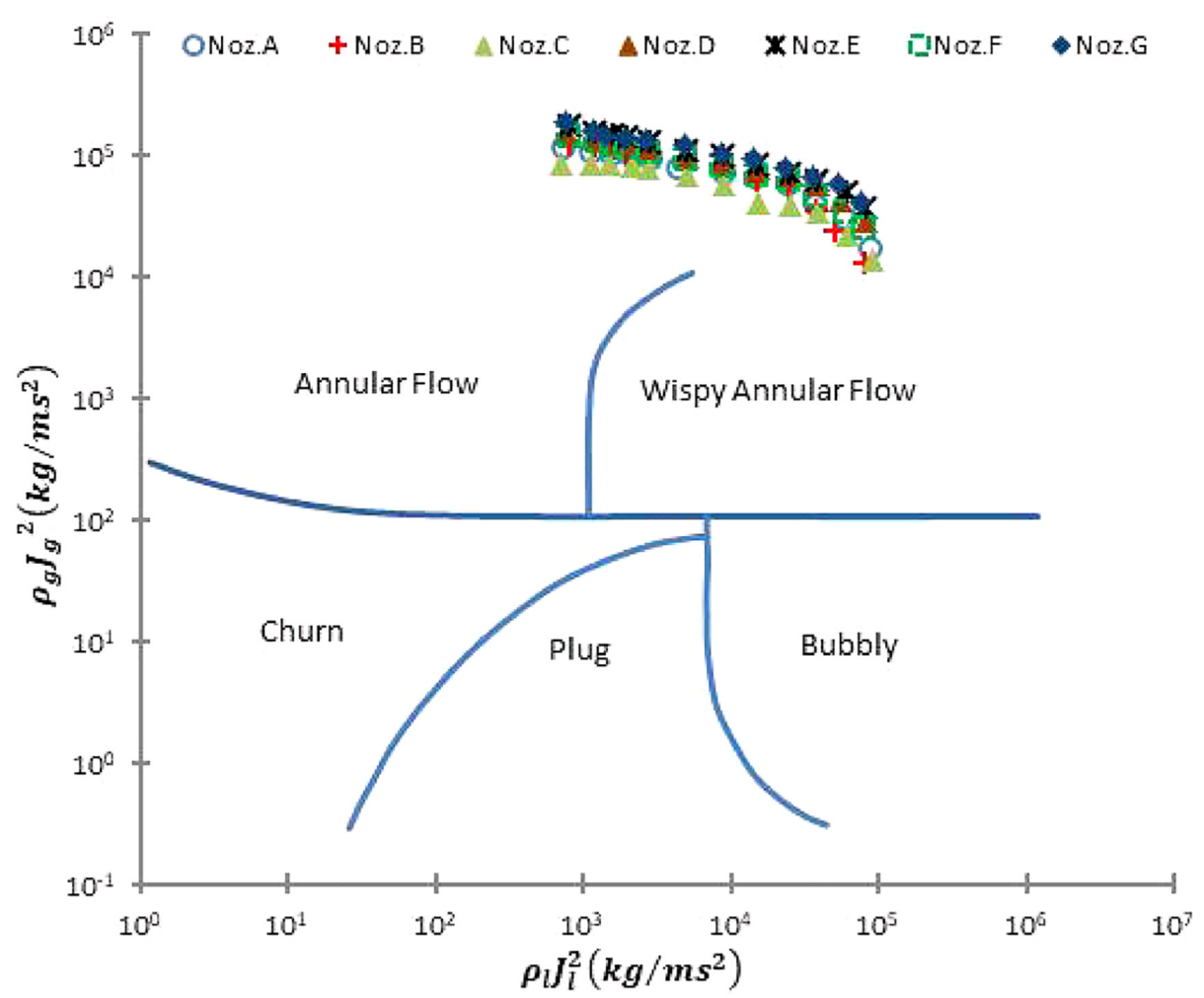

FIG. 12: Data points plotted on vertical multiphase pipe flow regime map of Hewitt and Roberts (1969)

Figure 13 shows the flow pattern map provided by Oshinowo and Charles (1974) for the vertical downward flow. In this figure, the ordinate is the square root of the air-liquid volumetric flow rate ratio, while the abscissa is the ratio of the two-phase Froude number, Fr ${ }_{\text {tp }}$, to the square root of $\mathrm{A}$, where

$$
\begin{gathered}
\mathrm{Fr}_{\mathrm{tp}}=\frac{U_{s}^{2}}{g d_{m}}, \\
A=\frac{\mu_{l}^{\prime}}{\left(\rho_{l}^{\prime} \sigma^{\prime 3}\right)^{0.25}},
\end{gathered}
$$

and $J$, the superficial velocity of the two-phase flow is obtained as

$$
J=\frac{Q_{a}+Q_{l}}{(\pi / 4) d_{m}^{2}}
$$

It can be clearly seen that the results lie outside the flow regime established by the map. Nevertheless, one could easily speculate from the map that for the very low GLRs used in the study, the flow has to be froth, or transition between froth and annular flow, while for higher values of GLR, the flow has to be annular; this result matches with the contours displayed in Fig. 11. 


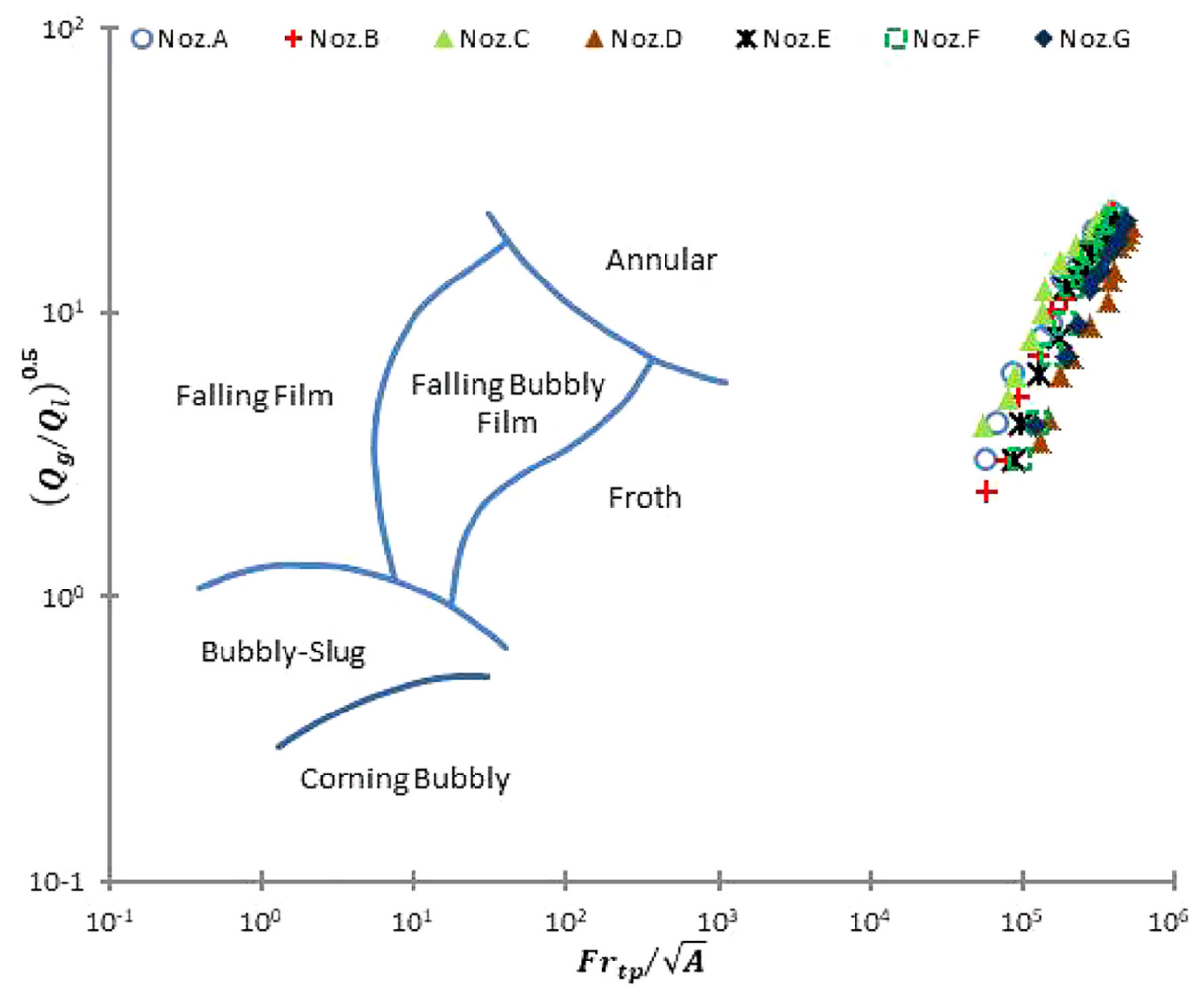

FIG. 13: Data points plotted on vertical multiphase pipe flow regime map of Oshinowo and Charles (1974)

\section{CONCLUSION}

A parametric analysis to study the effect of operational and geometric parameters on the internal flow characteristics of a twin-fluid Y-jet atomizer has been carried out; seven atomizers with different geometrical parameters have been considered. Moreover, 11 cases for each atomizer with different GLR (gas to liquid mass flow rate) ratios have been simulated, giving a total of 77 cases. The working fluids were water and air. The compressible Navier-Stokes equation was used to model the flow through the atomizer, utilizing its implementation into ANSYS Fluent. A hybrid RANS and LES technique, i.e., WMLES (wall modeled large eddy simulations) was used to resolve the larger eddies with LES simulation, while smaller eddies near the wall were modeled with the Prandtl length model. The volume of fluid method was used to capture the development and fragmentation of the gas-liquid interface inside the Y-jet atomizer. The results show that the gas-liquid multiphase regime formed is annular flow for the vast majority of GLR ratios. The sudden expansion of gas jet from the gas port into the mixing duct is limited by higher pressure of the liquid jet emanating from the liquid port; this leads to recirculation of the air in the premixed zone of the nozzle, which, in turn, results in reverse film formation in the premixed zone. The numerical results obtained have been compared with empirical correlations of the pressure drop for a twin-fluid Y-jet atomizer available in the open literature and have been found to agree well with them. These correlations could be used for designing a Y-jet atomizer, and predicting the occurrence of critical conditions at the exit of the gas port. Moreover, the results

Volume 29, Issue 5, 2019 
show that the mixing point pressure is strongly dependent on the mixing port to air port diameter ratio, specifically in the rage $0.1<(\mathrm{GLR})<0.4$; the mixing port length moderately affects the mixing point pressure while the angle between mixing and liquid ports was found not to have an appreciable effect. Despite some significant difference between the multiphase flow in pipes and the flow that could arise in the Y-jet atomizers, the classical pipe multiphase flow regime maps could be applied to the flow through the mixing duct of twin-fluid Y-jet atomizers. The main flow regimes found under the studied operational conditions are annular and wispy-annular flow.

\section{ACKNOWLEDGMENTS}

The project has received funding from European Union Horizon-2020 Research and Innovation MSCA-ITN Programme with acronym HAOS: Grant Agreement No. 675676.

\section{REFERENCES}

Andreussi, P., Tognotti, L., Michele, G.D., and Graziadio, M., Design and Characterization of Twin-Fluid Y-Jet Atomizers, Atomization Sprays, vol. 2, pp. 45-59, 1992.

Andreussi, P., Graziadio, M., Novelli, G., Pasqualetti, A., and Tognotti, L., Measurement of Film Thickness within a Y-Jet Atomizer, in Proc. of Int. Conf. on Liquid Atomization and Spray Systems, Rouen, France, pp. 632-639, 1994.

Arcoumanis, C., Gavaises, M., Argueyrolles, B., and Galzin, F., Modeling of Pressure-Swirl Atomizers for GDI Engines, SAE Trans., vol. 108-3, pp. 516-532, 1999a.

Arcoumanis, C., Gavaises, M., Abdul-Wahab, E., and Moser, V., Modeling of Advanced High-Pressure Fuel Injection Systems for Passenger Car Diesel Engines, SAE Trans., vol. 108-3, pp. 1347-1362, $1999 \mathrm{~b}$.

Barreras, F., Lozano, A., Barroso, J., and Lincheta, E., Experimental Characterization of Industrial TwinFluid Atomizers, Atomization Sprays, vol. 16, pp. 145-147, 2006a.

Barreras, F., Lozano, A., Ferreira, G., and Lincheta, E., Study of the Internal Flow Condition on the Behavior of Twin-Fluid Nozzle with Internal Mixing Chamber, in Proc. of ICLASS, Kyoto, Japan, $2006 \mathrm{~b}$.

Barreras, F., Lozano, A., Ferreira, G., and Lincheta, E., The Effect on the Inner Flow on the Performance of a Twin-Fluid Nozzle with an Iternal Mixing Chamber, in Proc. of ILASS_Europe Conf., Como, Italy, 2008.

Brackbill, J.U., Kothe, D.B., and Zemach, C., A Continum Method for Modeling Surface Tension. J. Comput. Phys., vol. 100, pp. 335-354, 1992.

Bryce, W., Cox, N., and Joyce, W., Oil Droplet Production and Size Measurement from a Twin-Fluid Atomizer Using Real Fluids, in Proc. of 3rd Int. Conf. on Liquid Atomization and Sprays, Tokyo, Japan, pp. 259-263, 1978.

Chin, J.S. and Lefebvre, A.H., Flow Patterns in Internal-Mixing Twin-Fluid Atomizers, Atomization Sprays, vol. 3, pp. 463-374, 1993.

Crowe, C., Multiphase Flow Handbook, New York, NY: Taylor and Francis, 2006.

Dafsari, R.A., Vashali, F., and Lee, J., Effect of Swirl Chamber Length on the Atomization Characteristics of a Pressure Swirl Nozzle, Atomization Sprays, vol. 27, no. 10, pp. 859-874, 2017.

De Michele, G., Graziadio, M., Morelli, F., and Novelli, G., Characterization of the Spray Structure of a Large Scale H.F.O. Atomizer, in Proc. ICLASS, Gaithersburg, MD, vol. 99, pp. 779-786, 1991.

Dombrowski, N., Hanson, D., and Ward, D., Some Aspects of Liquid Flow through Fan Spray Nozzles, Chem. Eng. Sci., vol. 12, pp. 33-50, 1960.

Dombrowski, N. and Johns, W., The Aerodynamic Instability and Disintegration of Viscous Liquid Sheets, Chem. Eng. Sci., vol. 8, no. 7, pp. 203-214, 1963. 
The Influence of Geometrical and Operational Parameters

El-Batsh, H.M., Doheim, M.A., and Hassan, A.F., On the Application of Mixture Model for Two-Phase Flow Induced Corrosion in a Complex Pipeline Configuration, Appl. Math. Modell., vol. 36, pp. 56865699, 2012.

Esfarjani, S.A. and Dolatabadi, A., 3D Simulation of Two-Phase Flow in an Effervescent Atomizer for Suspension Plasma Spray, Surf. Coat. Technol., vol. 203, pp. 2074-2280, 2009.

Ferreira, G., Barreras, F., Lozano, A., Garcia, J.A., and Lincheta, E., Effect of Inner Two-Phase Flow on the Performance of an Industrial Twin-Fluid Nozzle with an Internal Mixing Chamber, Atomization Sprays, vol. 19, pp. 873-884, 2009a.

Ferreria, G., Garcia, J.A., Barreras, F., Lozano, A., and Lincheta, E., Design and Optimization of TwinFluid Atomizers with an Internal Mixing Chamber for Heavy Fuel Oils, Fuel Process. Technol., vol. 90, pp. 270-278, 2009b.

Gadgil, H.P. and Raghunandan, B.N., Some Features of Spray Breakup in Effervescent Atomizers, Exp. Fluids, vol. 50, pp. 329-338, 2011.

Gopala, V.R. and Berend, G.M., Volume of Fluids Methods for Immiscible-Fluids and Free-Surface Flows, Chem. Eng. J., vol. 141, pp. 204-221, 2008.

Hawkes, N., Lawrence, C., and Hewitt, G., Studies of Wispy-Annular Flow Using Transient Pressure Gradient and Optical Measurement, Int. J. Multiphase Flow, vol. 26, pp. 1565-1582, 2000.

Hewitt, G.F. and Roberts, D.N., Studies of Two-Phase Flow Patterns by Simultaneous X-Ray and Flash Photography, Atomic Energy Research Establishment, Harwell, UK, Tech. Rep. AERE-M2159, Feburary, 1969.

Hinze, J.O., Turbulence, New York: McGraw-Hill, 1975.

Huang, X., Wang, X., and Liao, G., Characterization of an Effervescent Atomization Water Mist Nozzle and Its Fire Suppression Tests, Proc. Combust. Inst., vol. 33, pp. 2573-2579, 2011.

Jang, X., Siamas, G.A., Jagus, K., and Karayiannis, T., Physical Modelling and Advanced Simulations of Gas-Liquid Two-Phase Jet Flows in Atomization and Sprays, Prog. Energy Combust. Sci., vol. 36, pp. 131-167, 2010.

Kieffer, S.W., Sound Speed in Liquid-Gas Mixtures: Water-Air and Water-Steam, J. Geophys. Res., vol. 82, pp. 2895-2904, 1977.

Koukouvinis, P., Gavaises, M., Li, J., and Wang, L., Large Eddy Simulation of Diesel Injector Including Cavitation Effects and Correlation to Erosion Damage, Fuel, vol. 175, pp. 26-39, 2016 a.

Koukouvinis, P., Naseri, H., and Gavaises, M., Performance of Turbulence Models and Effect of Cavitation Models in Prediction of Incipient Cavitation, Int. J. Engine Res., vol. 18, pp. 333-350, 2016b.

Lakhehal, D., Meier, M., and Fulgosi, M., Interface Tracking towards the Direct Simulation of Heat and Mass Transfer in Multiphase Flows, Int. J. Heat Fluid Flow, vol. 23, pp. 242-257, 2002.

Lang, R., Ultrasonic Atomization of Liquids, J. Acoust. Soc. Am., vol. 34, no. 1, pp. 6-8, 1962.

Lefebvre, A.H., A Novel Method of Atomization with Potential Gas Turbine Application, Def. Sci. J., vol. 38, pp. 353-362, 1988.

Lefebvre, A.H., Twin-Fluid Atomization: Factors Influencing Mean Drop Size, Atomization Sprays, vol. 2, pp. 101-119, 1992.

Li, Z., Wua, Y., Cai, C., Zhang, H., Gong, Y., Takeno, K., Hashiguchi, K., and Lu, J., Mixing and Atomization Characteristics in an Internal-Mixing Twin-Fluid Atomizer, Fuel, vol. 97, pp. 306-314, 2012.

Li, S., Yang, X.Y., Fu, C., Li, T.Y., and Gao, Y., Experimental Investigation of Near-Field Breakup Characteristics of Hybrid-Mix Twin-Fluid Atomizers, Atomization Sprays, vol. 28, no. 10, pp. 901-914, 2018.

Loebker, D. and Empie, H.J., High Mass Flow Rate Effervescent Spraying of High Viscosity Newtonian Liquid, in Proc. of 10th Annual Conf. on Liquid Atomization and Spray Systems, Ottawa, Canada, pp. 253-257, 1997.

Volume 29, Issue 5, 2019 
Loth, E., Computational Fluid Dynamics of Bubbles, Drops and Particles, Cambridge, UK: Cambridge University Press, 2009.

Maski, D. and Durairaj, D., Effects of Electrode Voltage, Liquid Flow Rate, and Liquid Properties on Spray Chargeability of an Air-Assisted Electrostatic-Induction Spray, J. Electrost., vol. 68, no. 2, pp. 152-158, 2010.

McWilliam, D. and Duggins, R., Speed of Sound in Bubbly Liquids, Proc. Inst. Mech. Eng., vol. 184, no. 3, pp. 102-107, 1969.

Mitroglou, N. and Gavaises, M., Cavitation inside Real-Size Fully Transparent Fuel Injector Nozzles and Its Effect on Near-Nozzle Spray Formation, in Proc. of Workshop on Droplet Impact Phenomena and Spray Investigations (DIPSI), University of Bergamo, Italy, 2011.

Mlkvik, M., Stahle, P., Schuchmann, H.P., Gaukel, V., Jedelsky, J., and Jicha, M., Twin-Fluid Atomization of Viscous Liquids: The Effect of Atomizer Construction on Breakup Process, Spray Stability and Droplet Size, Int. J. Multiphase Flow, vol. 77, pp. 19-31, 2015.

Mujumdar, A.S., Huang, L.X., and Chen, X.D., An Overview of the Recent Advances in Spray-Drying, Dairy Sci. Technol., vol. 90, pp. 211-224, 2010.

Mullinger, P. and Chigier, N., The Design and Performance of Internal Mixing Multijet Twin Fluid Atomizers, J. Inst. Fuel, vol. 47, pp. 251-261, 1974.

Naseri, H., Trickett, K., Mitroglou, N., Karathanassis, I., Koukouvinis, P., Gavaises, M., Barbour, R., Santini, M., and Wang, J., Turbulence and Cavitation Suppression by Quaternary Ammonium Salt Additives, Nat. Sci. Rep., vol. 8, no. 7636, 2018.

Nazeer, Y., Ehmann, M., Koukouvinis, F., and Gavaises, M., Internal Flow Characteristics of Twin-Fluid ' $\mathrm{Y}$ ' Type Internally Mixing Atomizer, in Proc. of ICLASS, Chicago, IL, 2018.

Nguyen, D. and Rhodes, M.J., Producing Fine Drops of Water by Twin-Fluid Atomization, Powder Technol., vol. 99, pp. 285-292, 1998.

Oshinowo, T. and Charles, M.E., Vertical Two-Phase Flow; Part 1, Flow Pattern Correlations, J. Chem. Eng., vol. 52, pp. 25-35, 1974.

Pacifico, A.L. and Yanagihara, J.I., The Influence of Geometrical and Operational Parameters on Y-Jet Atomizers Performance, J. Braz. Soc. Mech. Sci. Eng., vol. 36, pp. 13-32, 2014.

Piomelli, U. and Balaras, E., Wall-Layer Models for Large-Eddy Simulations, Annu. Rev. Fluid Mech., vol. 34, pp. 349-374, 2002.

Prasad, K.S.L., Characterization of Air Blast Atomizers, in Proc. of ICLASS, Madison, WI, 1982.

Radcliffe, A., The Performance of a Type of Swirl Atomizer, Proc. Inst. Mech. Eng., vol. 169, pp. 93-106, 1955.

Saleh, A., Amini, G., and Dolatabadi, A., Penetration of Aerated Suspension on Spray in a Gaseous Crossflow, Atomization Sprays, vol. 28, no. 2, pp. 91-110, 2018.

Shur, M., Strelets, P., Spalart, M., and Travin, A., Detached-Eddy Simulation of an Airfoil at High Angle of Attack, Eng. Turbul. Modell. Meas., vol. 4, pp. 669-678, 1999.

Shur, M.L., Spalart, P.R., Strelets, M.K., and Travin, A.K., A Hybrid RANS-LES Approach with DelayedDES and Wall-Modelled LES Capabilities, Int. J. Heat Fluid Flow, vol. 29, pp. 1638-1649, 2008.

Smagorinsky, J., General Circulation Experiments with the Primitive Equations, Mon. Weather Rev., vol. 91, pp. 99-164, 1963.

Song, S. and Lee, S., An Examination of Spraying Performance of Y-Jet Atomizers-Effect of Mixing Port Length, in Proc. of ICLASS, Rouen, France, 1994.

Song, S.H. and Lee, S.Y., Study of Atomization Mechanism of Gas/Liquid Mixtures Flowing through Y-Jet Atomizers, Atomization Sprays, vol. 6, pp. 193-209, 1996.

Sovani, S., Sojka, P., and Lefebvre, A., Effervescent Atomization, Prog. Energy Combust. Sci., vol. 27, 
The Influence of Geometrical and Operational Parameters

no. 2, pp. 483-521, 2001.

Spalart, P., Jou, W., Strelets, M., and Allmaras, S., Comments on the Feasibility of LES for Wings, and on a Hybrid RANS/LES Approach, in Proc. of 1st AFOSR Int. Conf. on DNS/LES, Ruston, LA, 1997.

Spalart, P.R., Deck, S., Shur, M.L., Squires, K.D., Strelets, M.Kh., and Travin, A., A New Version of Detached-Eddy Simulation, Resistant to Ambiguous Grid Densities, Theor. Comput. Fluid Dyn., vol. 20, no. 3, pp. 181-195, 2006.

Tanasawa, Y., Miyasaka, Y., and Umehara, M., Effect of Shape of Rotating Disks and Cups on Liquid Atomization, in Proc. of ICLASS, Tokyo, Japan, pp. 165-172, 1978.

Tanner, F.X., Feigl, K., Karrio, O., and Windhab, E.J., Modeling and Simulation of Air-Assist Atomizers with Applications to Food Spray, Appl. Math. Models, vol. 40, pp. 6121-6133, 2016.

Tapia, Z. and Chavez, A., Internal Flow in Y-Jet Atomizer-Numerical Study, in Proc. of ILASS-Europe, Zaragoza, Spain, 2002.

Van Driest, E.R., On Turbulent Flow near a Wall, J. Aeronaut. Sci., vol. 23, pp. 1007-1011, 1956.

Wade, R.A., Weerts, J.M., Gore, J.P., and Eckerle, W.A., Effervescent Atomization at Injection Pressures in the MPa Range, Atomization Sprays, vol. 9, pp. 651-667, 1999.

Warnatz, J., Mass, U., and Dibble, R.W., Combustion: Physical and Chemical Fundamentals, Modeling and Simulation, Experiments, 3rd ed., Berlin: Springer-Verlag, 2001.

Wen, W. and Piomelli, U., Reynolds-Averaged and Wall-Modelled Large-Eddy Simulations of Impinging Jets with Embedded Azimuthal Vortices, Eur. J. Mech., B: Fluids, vol. 55, pp. 348-359, 2016.

Wigg, L., The Effect of Scales on Fine Sprays Produced by Large Airblast Atomiizer, Pyestock, UK: National Gas Turbine Establishment, 1959.

Zhou, Y., Zhang, M., Yu, J., and Zhu, X., Experimental Investigation and Model Improvement on the Atomization Performance of Single Hole Y-Jet Nozzle with High Liquid Flow Rate, Powder Technol., vol. 199, pp. 248-255, 2010.

\section{APPENDIX A. SPEED OF SOUND IN GAS-LIQUID MIXTURE}

Consider a unit-infinitesimal mixture of disperse phase (liquid) and continuous phase (gas). The initial densities are denoted by $\rho_{l}$ and $\rho_{g}$ and initial pressure in continuous phase by $P_{g}$. Surface tension, $\sigma$, can be included by denoting the radius of the dispersed phase particle by $R$. Then the initial pressure in the dispersed phase is $P_{l}=P_{g}+2 \sigma / R$.

Now consider an infinitesimal change in pressure $P_{l}$ to $P_{l}+\delta P_{l}$. Any dynamics associated with the resulting fluid motion is ignored. It is assumed that a new equilibrium state is achieved. In the absence of any mass exchange between the phases, the new dispersed and continuous phase volumes are, respectively,

$$
\begin{gathered}
\left(\rho_{l} \alpha_{l}\right) /\left[\rho_{l}+\left.\frac{\partial \rho_{l}}{\partial P_{l}}\right|_{s} \delta P_{l}\right], \\
\left(\rho_{g} \alpha_{g}\right) /\left[\rho_{g}+\left.\frac{\partial \rho_{g}}{\partial P_{g}}\right|_{s} \delta P_{g}\right] .
\end{gathered}
$$

Adding these together and subtracting from unity, one obtains the change in the total volume, $\delta V$, and hence sonic velocity $c$, as

$$
\frac{1}{c^{2}}=-\left.\rho \frac{\delta V}{\delta P_{g}}\right|_{\delta P_{g} \rightarrow 0},
$$

Volume 29, Issue 5, 2019 


$$
\frac{1}{\rho c^{2}}=\left.\frac{\alpha_{l}}{\rho_{l}} \frac{\partial \rho_{l}}{\partial P_{l}}\right|_{s} \frac{\delta P_{l}}{\delta P_{g}}+\left.\frac{\alpha_{g}}{\rho_{g}} \frac{\partial \rho_{g}}{\partial P_{g}}\right|_{s} .
$$

If we assume that no dispersed phase particles are created or destroyed, then the ratio $\delta P_{l} / \delta P_{g}$ could be determined by evaluating the new dispersed particle size $R+\delta R$ commensurate with the new disperse phase volume and using the relation $\delta P_{l}=\delta P_{g}-\left(2 \sigma / R^{2}\right) \delta R$ :

$$
\frac{\delta P_{l}}{\delta P_{g}}=\left[1 /\left(1-\left.\frac{2 \sigma}{3 \rho_{l} R} \frac{\partial \rho_{l}}{\partial P_{l}}\right|_{s}\right)\right] .
$$

Substituting this into Eq. (24) and using the notations

$$
\frac{1}{c_{l}^{2}}=\left.\frac{\partial \rho_{l}}{\partial P_{l}}\right|_{s} ; \quad \frac{1}{c_{g}^{2}}=\left.\frac{\partial \rho_{g}}{\partial P_{g}}\right|_{s},
$$

the result could be expressed as

$$
\frac{1}{\rho c^{2}}=\frac{\alpha_{g}}{\rho_{g} c_{g}^{2}}+\frac{\alpha_{l} / \rho_{l} c_{l}^{2}}{\left[1-2 \sigma / 3 \rho_{l} c_{l}^{2} R\right]} .
$$

For the sake of simplification, and in most practical circumstances the surface tension effect can be neglected since $\sigma \ll \rho_{l} c_{l}^{2} R$, then Eq. (27) could be expressed as

$$
\frac{1}{\rho c^{2}}=\frac{\alpha_{g}}{\rho_{g} c_{g}^{2}}+\frac{\alpha_{l}}{\rho_{l} c_{l}^{2}}
$$

$\rho c^{2}$ is the effective bulk modulus of the mixture where the effective density $\rho=\alpha_{g} \rho_{g}+\alpha_{l} \rho_{l}$ is governed by the density of the liquid and the inverse of the effective bulk modulus is equal to an average of the inverse bulk moduli of the components $\left(1 / \rho_{g} c_{g}^{2}\right.$ and $\left.1 / \rho_{l} c_{l}^{2}\right)$ weighted according to their volume fractions.

\section{APPENDIX B. GRID INDEPENDENT STUDY}

A grid independence study was conducted to check whether flow regimes change with the grid. Figure B1(a) shows the grid used in the parametric study for nozzle D and Fig. B1(b) shows the coarser grid. Grid "a" has about 17 million elements and grid "b" has around 13 million

(a)

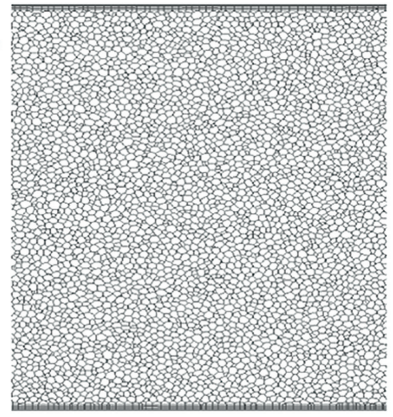

(b)

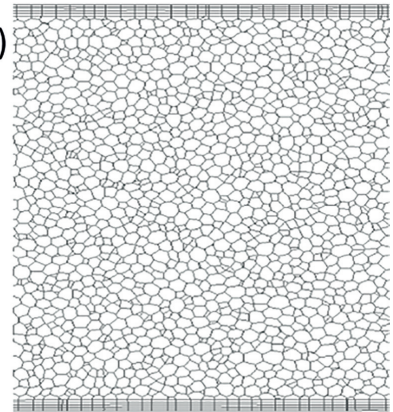

FIG. B1: (a) Grid used in the parametric study, (b) coarser grid 
elements. The total number of elements around the circumference of the mixing duct for grid "a" are 390 while for grid "b" they are 280 . The $\mathrm{Y}^{+}$value for grid "a" is 0.72 while for grid "b" it is 0.92 .

Figure B2 shows contours of the average volume fraction of water over 100,000 time steps. The time step size is $1 \times 10^{-8} \mathrm{~s}$. Figures B2(a) and B2(b) depict the average volume fraction for the froth/churn-turbulent flow regime $(G L R=0.01)$, Figs. B2(c) and B2(d) depict the average

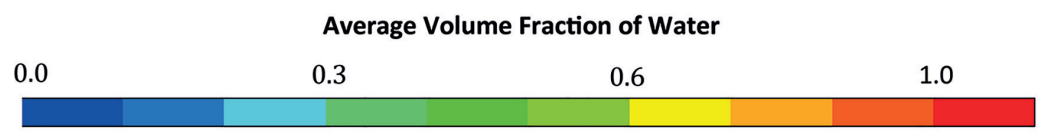

(a) Average volume fraction for grid ' $b$ ' with $G L R=0.01$

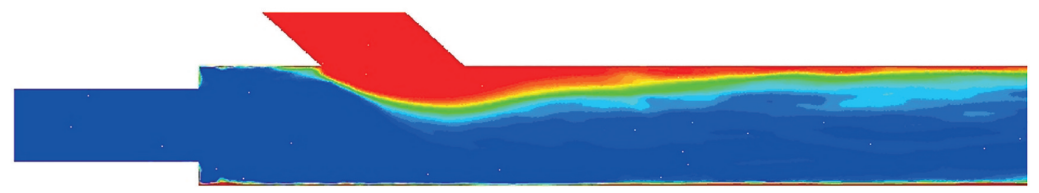

(b) Average volume fraction for grid ' $a$ ' with GLR=0.01

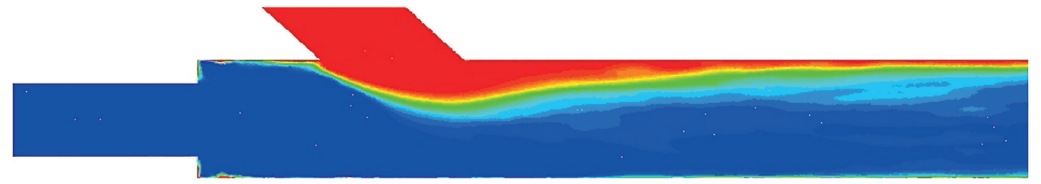

(c) Average volume fraction for Grid ' $b$ ' with GLR= 0.1

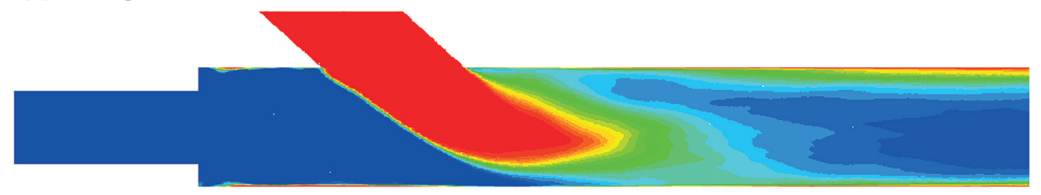

(d) Average volume fraction for grid ' $a$ ' with $G L R=0.1$

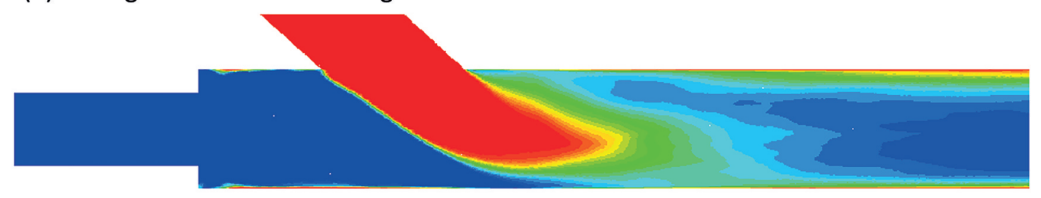

(e) Average volume fraction for grid ' $b$ ' with GLR=0.3

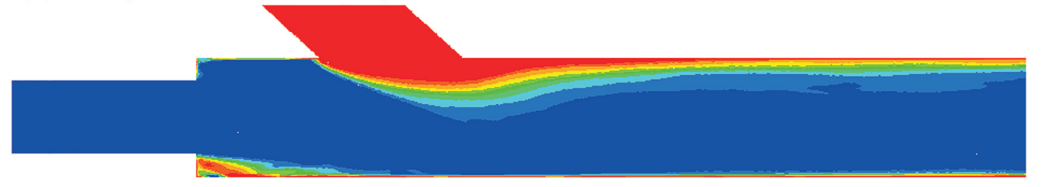

(f) Average volume fraction for grid ' $a$ ' with $G L R=0.3$

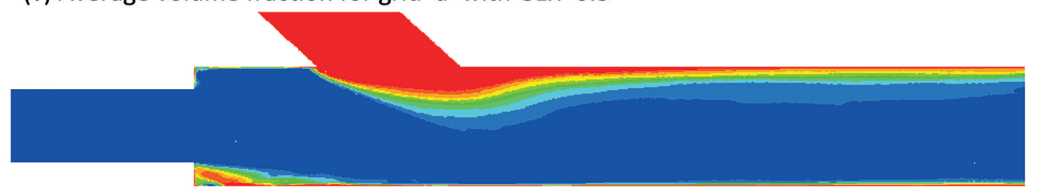

FIG. B2: Average volume fraction of water over 100,000 time steps (a), (b) average volume fraction for froth/churn-turbulent flow regime, (c), (d) average volume fraction for wispy-annular flow regime, and (e), (f) average volume fraction for annular flow regime

Volume 29, Issue 5, 2019 
volume fraction for the wispy-annular flow regime (GLR $=0.1$ ), and Figs. B2(e) and B2(f) depict the average volume fraction of the annular flow regime $(G L R=0.3)$. The average volume fraction of all three flow regimes is almost the same for coarser and dense grids. 